\title{
BMP signalling permits population expansion by preventing premature myogenic differentiation in muscle satellite cells
}

\author{
Y Ono ${ }^{1}$, F Calhabeu ${ }^{1}$, JE Morgan ${ }^{2}$, T Katagiri ${ }^{3}$, H Amthor ${ }^{4}$ and PS Zammit ${ }^{\star, 1}$
}

Satellite cells are the resident stem cells of adult skeletal muscle, supplying myonuclei for homoeostasis, hypertrophy and repair. In this study, we have examined the role of bone morphogenetic protein (BMP) signalling in regulating satellite cell function. Activated satellite cells expressed BMP receptor type 1A (BMPR-1A/Alk-3) and contained phosphorylated Smad proteins, indicating that BMP signalling is operating during proliferation. Indeed, exogenous BMP4 stimulated satellite cell division and inhibited myogenic differentiation. Conversely, interfering with the interactions between BMPs and their receptors by the addition of either the BMP antagonist Noggin or soluble BMPR-1A fragments, induced precocious differentiation. Similarly, blockade of BMP signalling by siRNA-mediated knockdown of BMPR-1A, disruption of the intracellular pathway by either Smad5 or Smad4 knockdown or inhibition of Smad1/5/8 phosphorylation with Dorsomorphin, also caused premature myogenic differentiation. BMP signalling acted to inhibit the upregulation of genes associated with differentiation, in part, through regulating Id1. As satellite cells differentiated, Noggin levels increased to antagonise BMP signalling, since Noggin knockdown enhanced proliferation and impeded myoblast fusion into large multinucleated myotubes. Finally, interference of normal BMP signalling after muscle damage in vivo perturbed the regenerative process, and resulted in smaller regenerated myofibres. In conclusion, BMP signalling operates during routine satellite cell function to help coordinate the balance between proliferation and differentiation, before Noggin is activated to antagonise BMPs and facilitate terminal differentiation.

Cell Death and Differentiation (2011) 18, 222-234; doi:10.1038/cdd.2010.95; published online 6 August 2010

Muscle satellite cells are the resident stem cells of skeletal muscle and supply myonuclei for postnatal muscle growth, and for maintenance and repair in adult. ${ }^{1}$ Satellite cells are located on the surface of myofibres and are mitotically quiescent in healthy adult muscle. In response to cues for routine myofibre homoeostasis or hypertrophy, or the sporadic demands of muscle repair, satellite cells are activated to generate myoblasts that proliferate and eventually undergo myogenic differentiation to provide new myonuclei. Satellite cells also self-renew, thus maintaining a population of quiescent, undifferentiated precursors available to respond to repeated demand. ${ }^{2-4}$

Satellite cell function is controlled by various regulatory pathways, chief amongst them being Notch/Delta and Wnt signalling. ${ }^{1}$ Many of these same regulatory networks also control embryonic myogenesis, in addition to many other processes, both during development and repair in adult. Another important network for organising embryonic and foetal myogenesis involves the Bone morphogenetic proteins (BMPs). BMPs belong to the transforming growth factor- $\beta$ family and initiate signalling by binding to the transmembrane type 1 and type 2 BMP receptors (BMPRs). On BMP binding, type 1 and 2 receptors complex on the cell surface, allowing the constitutively active kinase of the type 2 receptor to transphosphorylate the type 1 receptor. ${ }^{5}$ This in turn phosphorylates the R-Smads - Smad1, Smad5 and Smad8 (pSmad1/5/8) - which translocate to the nucleus to regulate transcription of target genes including $I d s .{ }^{6-8}$ Inhibitor of differentiation/DNA-binding (Id) proteins (comprising Id1 1, 2, 3, 4) bind ubiquitously expressed E-proteins to form inactive heterodimers, thereby preventing the same E-proteins from binding with tissue-specific transcription factors such as MyoD and myogenin, a step necessary for their efficient function. ${ }^{9}$ BMP signalling can be modified in a number of ways, including through secreted antagonists such as Noggin, which bind BMPs with high affinity to interfere with interactions between BMPs and their receptors. ${ }^{5}$

Although crucial for bone and cartilage formation and repair, ${ }^{5,10}$ BMPs also inhibit myogenic differentiation to prevent ectopic myogenesis in the lateral plate mesoderm.

\footnotetext{
${ }^{1}$ King's College London, Randall Division of Cell and Molecular Biophysics, New Hunt's House, Guy's Campus, London SE1 1UL, UK; ${ }^{2}$ Dubowitz Neuromuscular Centre, UCL Institute of Child Health, 30 Guilford Street, London WC1N 1EH, UK; ${ }^{3}$ Division of Pathophysiology, Research Centre for Genomic Medicine, Saitama Medical University, 1397-1 Yamane, Hidaka-shi, Saitama 350-1241, Japan and ${ }^{4}$ UPMC INSERM, UMR S 974/CNRS UMR 7215, Institut de Myologie, 105 bd de l'Hôpital, 75013 Paris, France

${ }^{*}$ Corresponding author: PS Zammit, King's College London, Randall Division of Cell and Molecular Biophysics, New Hunt's House, Guy's Campus, London SE1 1UL, UK. Fax: + 44207848 6435; E-mail: peter.zammit@kcl.ac.uk

Keywords: satellite cell; BMP; Noggin; Smad; Id1; skeletal muscle

Abbreviations: BMP, bone morphogenetic protein; BMPR-1A, bone morphogenetic protein receptor type $1 \mathrm{~A} / \mathrm{Alk}-3$; sBMPR-1Af, soluble bone morphogenetic protein receptor $1 A$ fragments; caBMPR-1A, constitutively active bone morphogenetic protein receptor type $1 A$; pSmad1/5/8, phosphorylated Smad1, Smad5 and Smad8; Id, inhibitor of differentiation/DNA-binding protein; FOP, Fibrodysplasia ossificans progressiva; EDL, extensor digitorum longus; MyHC, myosin heavy chain; CKM, Muscle creatine kinase; DAPI, 4,6-diamidino-2-phenylindole; T0, freshly isolated; T48, cultured for $48 \mathrm{~h}$; T72, cultured for $72 \mathrm{~h}$

Received 17.12.09; revised 14.6.10; accepted 15.6.10; Edited by R De Maria; published online 06.8.10
} 
In the dermomyotome, however, BMP signalling itself must be inhibited, to permit the onset of myogenesis. ${ }^{11-14}$ BMPs not only impede myogenic differentiation in immortalised myogenic cell lines (e.g., C2) and primary myogenic cells in vitro but also induce osteoblastic gene expression and differentiation towards the osteoblast lineage. ${ }^{15-18}$ Interestingly, although able to express early markers of osteogenic differentiation such as alkaline phosphatase, many primary myogenic cells also retain expression of proteins associated with myogenesis (e.g., Pax7 and MyoD) after exposure to BMPs for several days. ${ }^{15,17}$ As intramuscular injection of certain BMPs (e.g., BMP2 and BMP4) can lead to ectopic bone formation in vivo, ${ }^{19,20}$ these in vitro observations were thought to provide mechanistic insight into Fibrodysplasia ossificans progressiva (FOP), a rare disorder of skeletal malformations and progressive extra-skeletal ossification in muscle. FOP is caused by a mutation in $A L K-2$, which renders this BMPR type 1 (BMPR-1) constitutively active, ${ }^{19}$ and inhibition of this mutant ALK-2 reduces ossification. ${ }^{21} \mathrm{How}-$ ever, Lounev et al. ${ }^{20}$ have recently shown that few $(<5 \%)$ muscle progenitors actually contribute to BMP-induced heterotopic ossification in vivo.

In this study, we investigated the role of BMP signalling in satellite cell function during adult myogenesis. During activation and proliferation, satellite cells robustly express BMPR$1 \mathrm{~A}$ (Alk-3), with pSmad1/5/8 and Smad4 present in their nuclei, indicative of operational BMP signalling. Exogenous BMP4 can sustain satellite cell division and reduce differentiation, with BMP4 functioning through BMPR-1A. Conversely, antagonising the interaction of BMP with its receptors or perturbing intracellular BMP signalling by either inhibiting Smad1/5/8 phosphorylation or reducing Smad5 or Smad4 levels, all induced premature differentiation. Manipulation of BMP signalling affected Id1 levels: a known inhibitor of differentiation that regulates the function of the myogenic regulatory factors (that comprise of Myf5, MyoD, myogenin and MRF4) through sequestration of E-proteins. Satellite cell progeny then upregulate the BMP antagonist Noggin as they differentiate, and knockdown of Noggin enhanced proliferation and impeded differentiation. As blockade of BMP signalling after muscle injury hindered regeneration, our observations show that BMP signalling is a potent regulator of routine satellite cell function in adult.

\section{Results}

BMP pathway proteins are present in activated and proliferating satellite cells. Satellite cell function can be modelled in vitro. On stimulation by mitogen-rich medium (termed plating or proliferation medium here), isolated Pax7-expressing quiescent satellite cells are activated and upregulate MyoD. Satellite cells then proliferate, before either downregulating Pax7, maintaining MyoD, inducing myogenin and proceeding to differentiate, or downregulating MyoD and maintaining Pax7, to return to a quiescent-like state, modelling self-renewal. ${ }^{2,3}$

To first determine the expression profile of BMPR-1A, we immunostained satellite cells retained in their niche on myofibres isolated from the extensor digitorum longus (EDL) muscle. BMPR-1A was undetectable in the vast majority of quiescent satellite cells on freshly isolated (T0) myofibres (Figure 1a). However, after culturing in plating medium for 48 (T48) or $72 \mathrm{~h}$ (T72), BMPR-1A became robustly expressed in activated and proliferating satellite cells (Figure 1a). BMPR$1 B$ was not detectable by Q-PCR (data not shown), consistent with its absence in $\mathrm{C} 2 \mathrm{C} 12$ myoblasts. ${ }^{22}$ Intracellular BMP signalling through BMPR-1A operates by phosphorylation of the carboxyl terminal of R-Smad proteins. Immunostaining for either pSmad $1 / 5 / 8$ or Smad5, revealed a strong nuclear signal in activated and proliferating (T48 and T72), but not quiescent (T0), satellite cells (Figure $1 \mathrm{~b}$ and $\mathrm{c}$ ). The common-mediator Smad (Co-Smad) Smad4, which facilitates translocation of Smad1/5/8 to the nucleus and promotes their transcriptional activity, ${ }^{5}$ was also present in the nuclei of activated satellite cells (Figure 1c). Thus, the expression dynamics of BMPR1A, pSmad1/5/8, Smad4 and Smad5 mirror each other, and indicate that BMP signalling is operating in activated and proliferating satellite cells.

As Noggin-mediated BMP antagonism contributes to initiation of the myogenic programme during embryogenesis, ${ }^{13}$ we hypothesised that Noggin may also modify BMP signalling in satellite cells. Noggin was undetectable in quiescent (TO), and at low levels in activated $\mathrm{Pax} 7^{+}$, satellite cells (Figure $2 a$ and $b$ ). In contrast, Noggin was highly expressed by differentiating myoblasts at T72, as shown by co-immunostaining for Noggin and myogenin (Figure 2b). Culturing satellite cells attached to a myofibre provides a useful model for studying satellite cell activation, proliferation and the initial stages of differentiation. Later events, such as myoblast fusion into large multi-nucleated myotubes, however, are better studied in satellite cells isolated from their associated myofibre and plated onto Matrigel-coated culture dishes. Such plated satellite cell-derived myoblasts cultured in differentiation medium for 2 days clearly exhibited high Noggin levels in myotubes and other Pax $7^{-}$cells (Figure $2 c$ and d).

BMP regulates the balance between proliferation and differentiation in satellite cells. We next examined the effects of stimulating BMP signalling, and used administration of recombinant BMP4 to achieve this, as it is present in serum. ${ }^{23}$ Addition of recombinant BMP4 protein $(100 \mathrm{ng} / \mathrm{ml})$ to EDL satellite cells retained in their niche on the myofibre significantly increased the number of $\mathrm{Pax} 7^{+} \mathrm{MyoD}^{+}$satellite cells, but decreased the number of cells with the differentiating $\mathrm{Pax}^{-} \mathrm{MyoD}^{+}$phenotype (Figure 3a). Inhibition of differentiation by BMP4 was confirmed by co-immunostaining for myogenin and Pax7 (Figure 3b). Plating medium contains chick embryo extract and horse serum, hence is rich in growth factors, and also contains BMP4. ${ }^{23}$ Under these culture conditions, satellite cell proliferation is likely to be near maximal; hence, addition of BMP4 did not further increase cell division (Figure $3 \mathrm{a}$ and b). As satellite cells retained expression of genes associated with myogenesis, these short exposures to BMP4 did not induce any obvious loss of myogenic identity.

To interfere with BMP binding to its receptors, we added recombinant Noggin protein $(50 \mathrm{ng} / \mathrm{ml})$ or soluble BMPR-1A fragments (sBMPR-1Af; $200 \mathrm{ng} / \mathrm{ml}$ ) to cultures of satellite cells associated with a myofibre for $72 \mathrm{~h}$. Exposure to either Noggin 
a

T0

T48
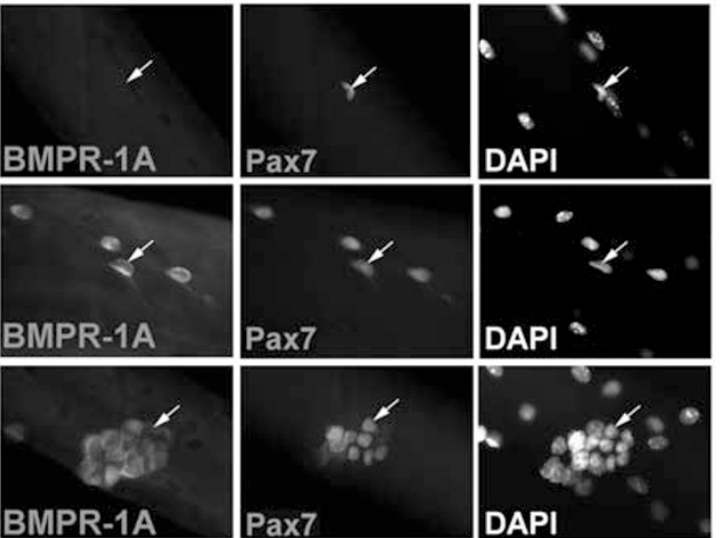

T72

BMPR-1

b

T0

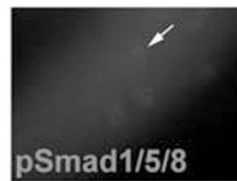

T48

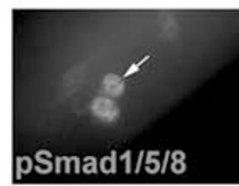

T72

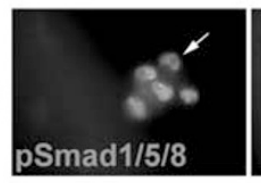

c

T0

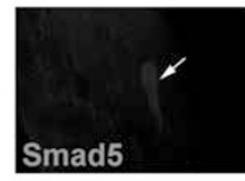

T48

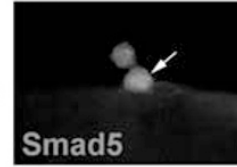

T48
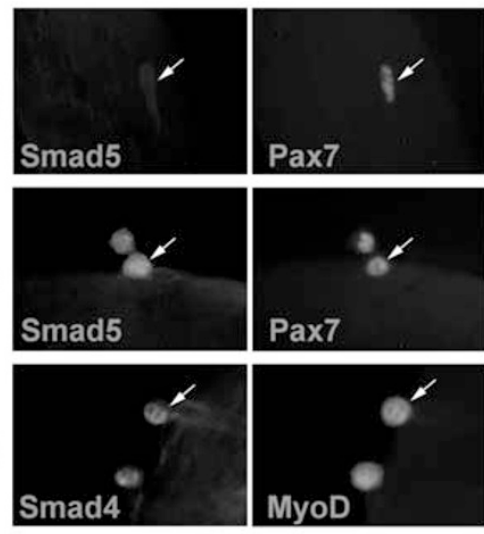

DAPI

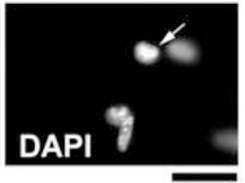

Figure 1 BMPR-1A, pSmad 1/5/8, Smad4 and Smad 5 are upregulated during satellite cell activation. Isolated EDL myofibres with their associated satellite cells were either immediately fixed (T0) or cultured in plating medium for either $48 \mathrm{~h}$ (T48) or $72 \mathrm{~h}$ (T72) before fixation and immunostaining. (a) BMPR-1A was undetectable on the majority of $\mathrm{Pax}^{+}$quiescent cells at $\mathrm{TO}$, but robustly expressed in both $\mathrm{Pax}^{+}$and Pax $7^{-}$cells at both T48 and T72. (b) Quiescent Pax $7^{+}$satellite cells (T0) did not contain $\mathrm{pSmad} 1 / 5 / 8$, whereas $\mathrm{pSmad} 1 / 5 / 8$ became readily detectable in the nuclei of proliferating Pax $7^{+}$cells at T48, and both $\mathrm{Pax}^{+}$and $\mathrm{Pax} 7^{-}$cells at T72. (c) In accordance with the dynamics of pSmad1/5/8 expression, Smad5 levels were very low/absent in quiescent satellite cells at T0, but upregulated in both proliferating $\mathrm{Pax}^{+}$and $\mathrm{MyoD}^{+}$cells at $\mathrm{T} 48$, as was Smad4. Arrows indicate the same satellite cell at each time point to aid comparison. Representative images from at least three independent experiments are shown. Scale bar equals $30 \mu \mathrm{m}$ a
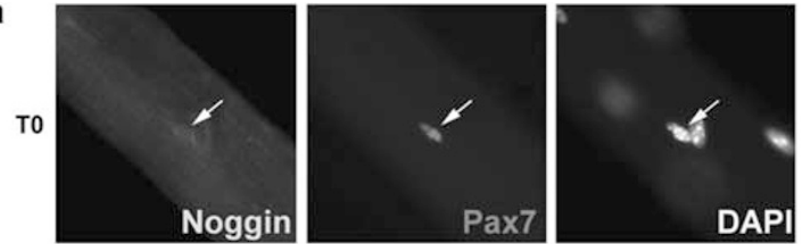

b
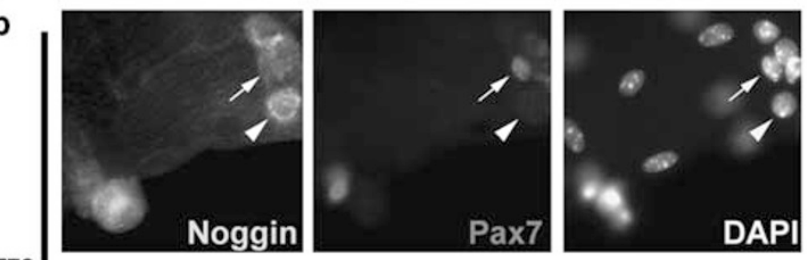

$\mathrm{T72}$
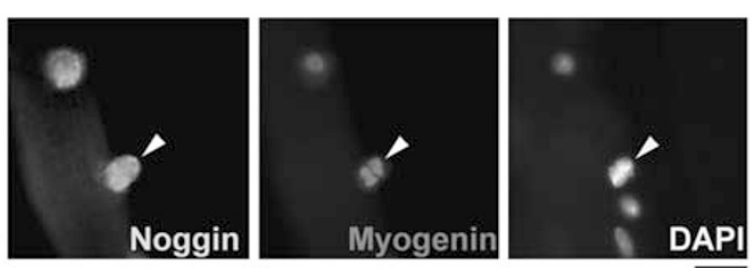

C
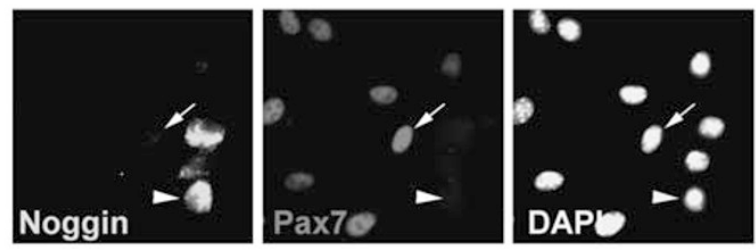

d
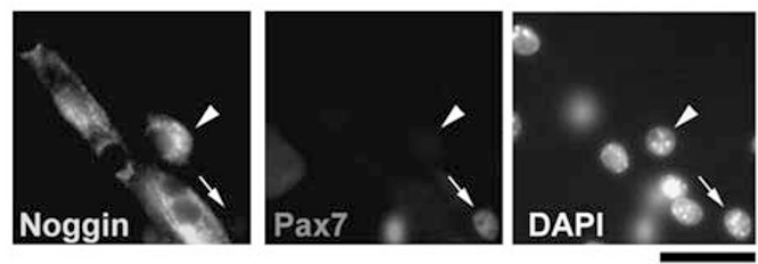

Figure 2 Noggin is highly expressed in satellite cell progeny committing to myogenic differentiation. Isolated EDL myofibres with their associated satellite cells were either immediately fixed (T0) or cultured in plating medium for $72 \mathrm{~h}$ (T72) before fixation and immunostaining. (a) Noggin was not expressed in quiescent $\mathrm{Pax}^{+}$satellite cells (arrows) at TO. (b) After culture, Noggin was highly expressed in both $\mathrm{Pax}^{-}$and Myogenin ${ }^{+}$cells committed to myogenic differentiation (arrowheads) at $\mathrm{T72}$, but at much lower levels in $\mathrm{Pax}^{+}$cells (arrows). (c and d) Plated satellite cell-derived myoblasts were cultured in differentiation medium for 2 days and immunostained for Noggin and Pax7. (c) Pax7 differentiating cells (arrowheads) and (d) myotubes both expressed high levels of Noggin protein, while Noggin levels in $\mathrm{Pax}^{+}$cells were low (arrows). Representative images from at least three independent experiments are shown. Scale bar equals $30 \mu \mathrm{m}$

or SBMPR-1Af resulted in a significant reduction in the mean total satellite cell number per myofibre, particularly of cells with the $\mathrm{Pax}^{+}{ }^{+} \mathrm{MyoD}^{+}$phenotype (Figure 3a). Numbers of differentiating $\mathrm{Pax}^{-} \mathrm{MyoD}^{+}$cells were already increased at $\mathrm{T} 48$, and became the predominant phenotype at T72, signifying a precocious onset of differentiation (Figure 3a). There were also significantly fewer self-renewing Pax ${ }^{+}$MyoD $^{-}$cells present at T72 (Figure $3 a$ ). Co-immunostaining for Pax7 and myogenin confirmed that both Noggin and sBMPR-1Af enhanced differentiation, revealing a significant increase in cells with the $\mathrm{Pax} 7^{-}$myogenin ${ }^{+}$ 
a

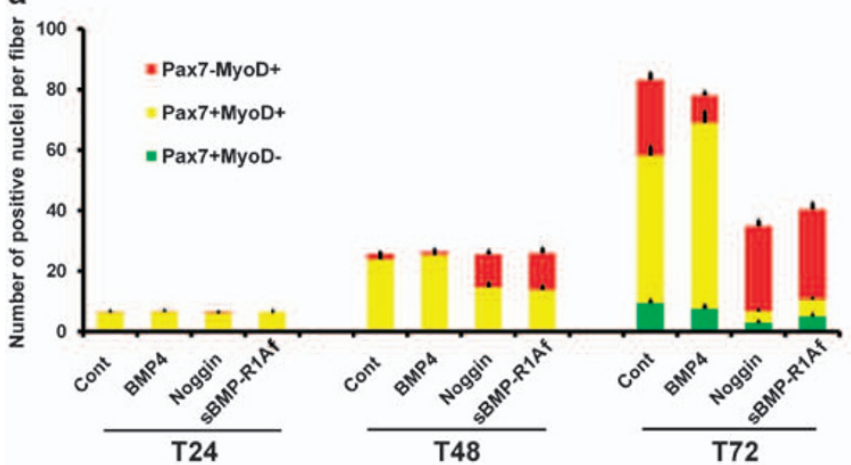

C

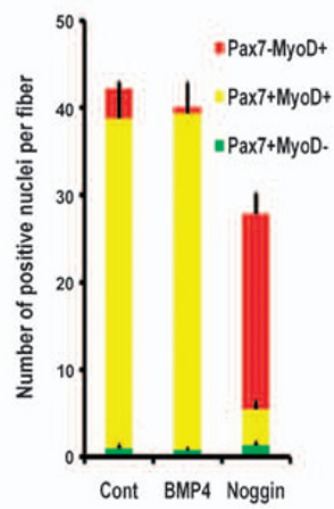

b

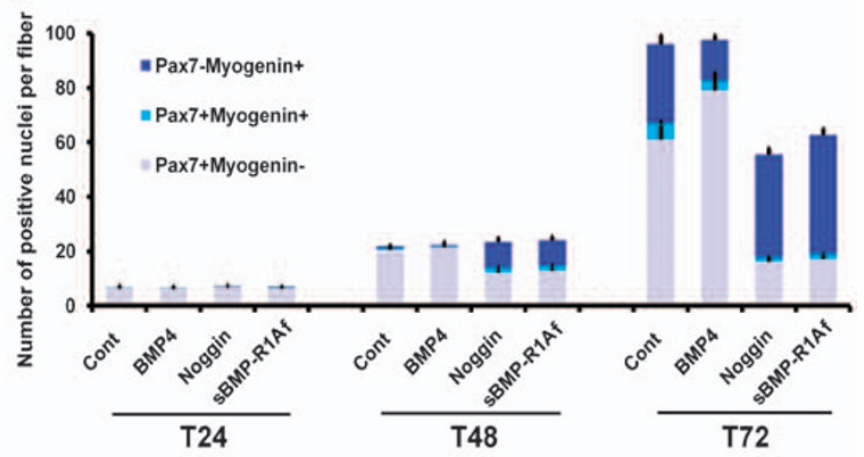

e

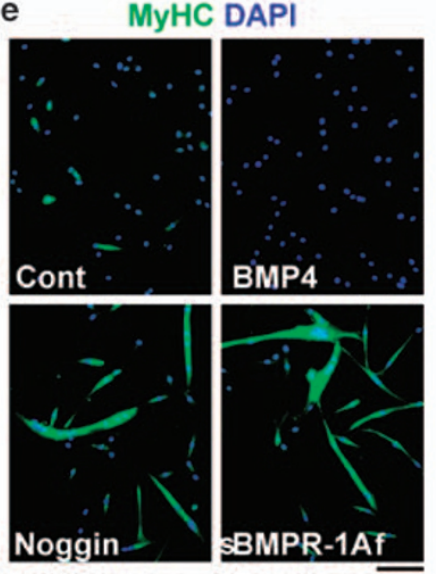

h

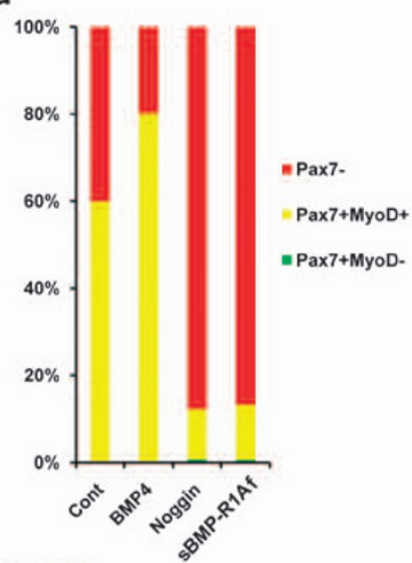

f

i

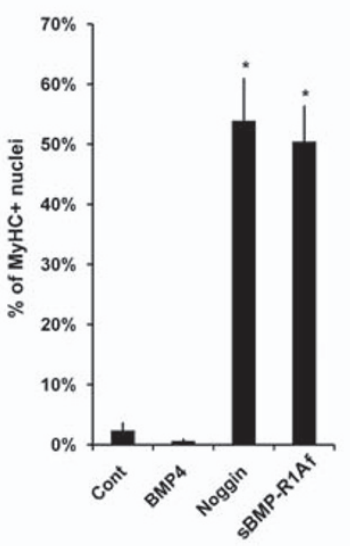

j g

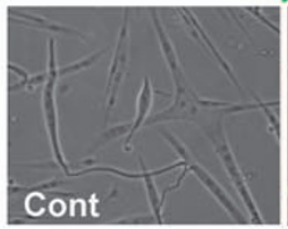

MyoD Myogenin DAPI

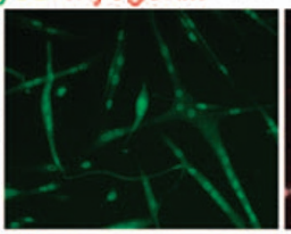

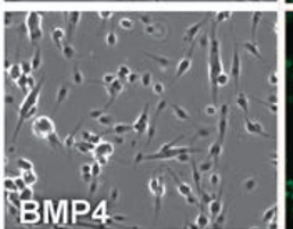
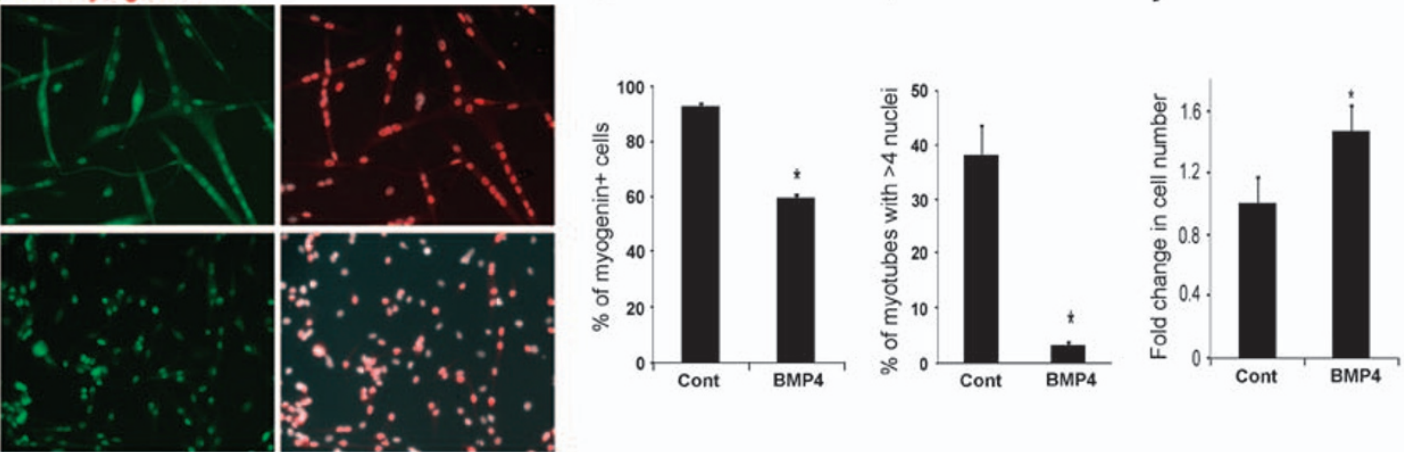

Figure 3 Inhibition of BMP signalling promotes myogenic differentiation in satellite cells. Isolated myofibres associated with satellite cells, or plated satellite cell-derived myoblasts, were cultured in the presence of recombinant BMP4 protein $(100 \mathrm{ng} / \mathrm{ml})$, recombinant Noggin protein $(50 \mathrm{ng} / \mathrm{ml})$ or sBMPR-1Af (200 ng/ml). (a) EDL myofibres were cultured in plating medium supplemented with BMP4, Noggin or sBMPR-1Af, then fixed after 24 (T24), 48 (T48) or 72 (T72) h and immunostained for Pax7 and MyoD. BMP4 reduced the number of Pax $7^{-} \mathrm{MyoD}^{+}$cells. Both Noggin and sBMPR-1Af reduced the mean total number of cells per myofibre and promoted myogenic differentiation (increase of the Pax7 ${ }^{-}$MyoD ${ }^{+}$phenotype). (b) Co-immunostaining isolated myofibres for Pax7, and myogenin confirmed that BMP4 inhibited myogenic differentiation, whereas Noggin and sBMPR-1Af promoted it, as shown by the increase of satellite cell progeny with the Pax7 $7^{-}$myogenin ${ }^{+}$phenotype. (c) Treatment of masseter-derived satellite cells with BMP4 or Noggin for $72 \mathrm{~h}$ produced the same result as for EDL cells, that is, BMP4 inhibited, whereas Noggin induced, myogenic differentiation. (d-f) To examine the effects of these recombinant proteins on the later stages of myogenesis, EDL satellite cells were plated and cultured in the presence of recombinant BMP4, Noggin or sBMPR-1Af in plating medium for 4 days (with the medium changed every other day). (d) Co-immunostaining for Pax7 and MyoD again showed a dramatic increase in the proportion of cells with the differentiating Pax $7^{-}$phenotype when exposed to either Noggin or SBMPR-1Af. (e, quantified in f) Immunostaining for MyHC revealed that exposure to either Noggin or sBMPR1 Af resulted in precocious differentiation and formation of large multi-nucleated myotubes. ( $\mathbf{g}-\mathbf{j})$ To better examine the effects of BMP on satellite cell proliferation and myogenic progression, plated satellite cells were also cultured in differentiation medium supplemented with recombinant BMP4 protein ( $200 \mathrm{ng} / \mathrm{ml})$ and immunostained for MyoD and myogenin ( $\mathbf{g}$, quantified in $\mathbf{h}-\mathbf{j})$. Exposure to BMP4 significantly reduced the proportion of cells expressing myogenin (h) and fusing into large myotubes (i), but stimulated continued cell proliferation, resulting in a $1.46 \pm 0.2$-fold increase in total cell number (j). Data are mean \pm S.E.M. (a-c) or mean \pm S.D. (f-j) from at least three independent experiments. Asterisk indicates that data are significantly different from controls $(P<0.05)$ using Student's $t$-test. Scale bar equals $100 \mu \mathrm{m}$ for $\mathbf{e}$

phenotype (Figure $3 b$ ). These effects were not restricted to satellite cells from somite-derived muscles, as those from the branchiomeric masseter muscle, which has a different embryonic origin, ${ }^{24}$ also exhibited fewer differentiating $\mathrm{Pax}^{-} \mathrm{MyoD}^{+}$cells in the presence of BMP4, but increased differentiation when exposed to Noggin (Figure 3c). 
Culture in proliferation medium does not readily support differentiation of plated satellite cells. Addition of recombinant BMP4 resulted in a higher proportion of cells co-immunostained for Pax7 and MyoD (Figure 3d). The differentiation index under these culture conditions, however, is already so low that any inhibitory effect of BMP4 on formation of myosin heavy chain $(\mathrm{MyHC})$ containing myocytes was not significant (Figure $3 e$, quantified in $f$ ). Addition of either Noggin or sBMPR-1Af, however, triggered a robust differentiation, as shown by both the reduced proportion of plated cells with Pax7 (Figure 3d) and the marked increase in myotubes containing $\mathrm{MyHC}$ (Figure $3 \mathrm{e}$ and $\mathrm{f}$ ). The proportion of satellite cell progeny with the self-renewing $\mathrm{Pax}^{+} \mathrm{MyoD}^{-}$phenotype was also significantly increased, from effectively zero in control cultures to $\sim 0.7 \%$ after exposure to either Noggin or sBMPR-1Af (Figure 3d).

Finally, we determined the effects of exogenous BMP4 on satellite cells after serum deprivation, which normally promotes myogenin expression, cell cycle exit and fusion into myotubes. However, addition of recombinant BMP4
(200 $\mathrm{ng} / \mathrm{ml})$ to differentiation medium led to a significant drop in the proportion of cells containing myogenin (Figure $3 \mathrm{~g}$, quantified in $\mathrm{h}$ ) and fusing into myotubes (Figure $3 \mathrm{~g}$, quantified in i). On the other hand, MyoD remained readily detectable in the nuclei of these cells after exposure to BMP4 for 2 days (Figure $3 \mathrm{~g}$ ). Importantly, BMP4 caused a $1.46 \pm 0.2$-fold increase in total cell number, indicating that BMP4 not only inhibits differentiation but also stimulates satellite cell proliferation, despite serum depletion (Figure 3j).

BMP operates through BMPR-1A to prevent precocious differentiation. To determine whether BMP signalling was transduced through BMPR-1A in activated satellite cells, we used siRNA-mediated knockdown, ${ }^{25}$ which reduced the mean total number of satellite cells per myofibre when assayed at T72 (Figure 4a, quantified in b). In particular, BMPR-1A knockdown significantly decreased the number of both $\mathrm{Pax}^{+}{ }^{+}$MyoD ${ }^{+}$cells and $\mathrm{Pax}^{+}{ }^{+}$MyoD ${ }^{-}$self-renewed cells, but not the number of $\mathrm{Pax} 7^{-} \mathrm{MyoD}{ }^{+}$differentiating cells, which became the predominant phenotype (Figure $4 \mathrm{~b}$ ).
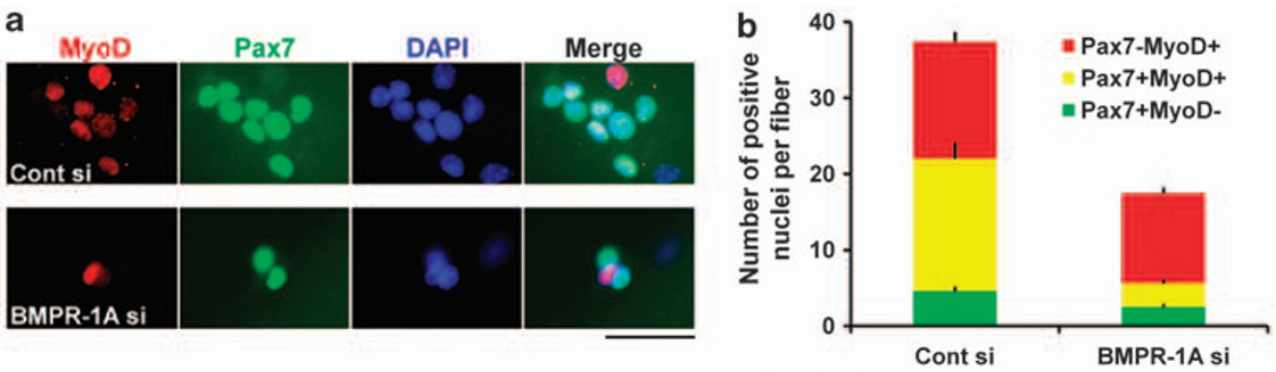

C

d

MyHC Ki67 DAPI

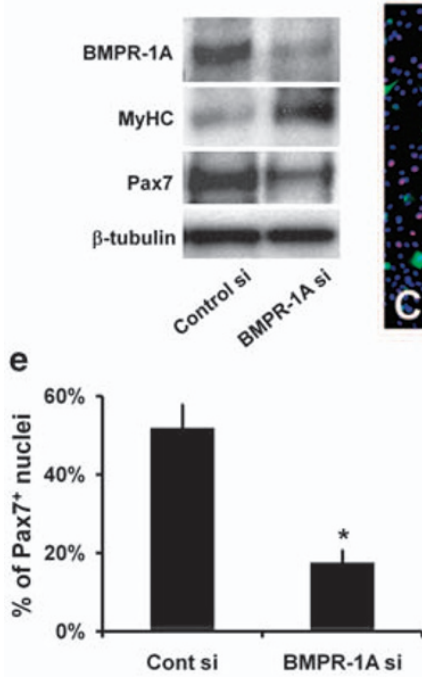

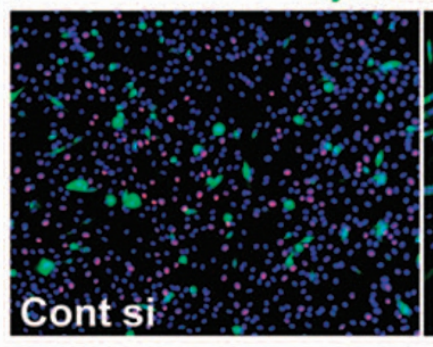

f

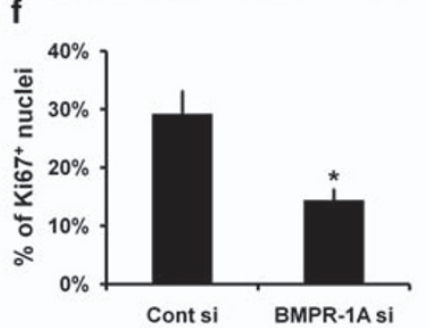

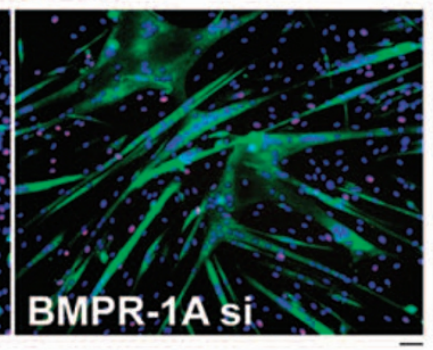

g

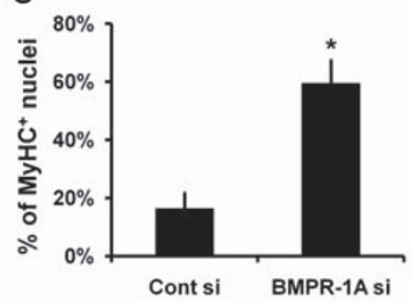

Figure 4 BMP signalling functions through BMPR-1A. We used siRNA-mediated protein knockdown to explore whether BMP signalling operates through BMPR-1A. (a, quantified in b) Control (Cont si) or BMPR-1A (BMPR-1Asi) siRNA were transfected into satellite cells retained in their niche on isolated EDL myofibers and cultured for $\sim 2.5$ days before fixation and co-immunostaining for Pax7 and MyoD. BMPR-1A knockdown reduced the mean total number of cells, especially the number of $\mathrm{Pax}^{+} \mathrm{MyoD}^{+}$cells. (c-g) Control siRNA or BMPR-1A siRNA duplexes were also transfected into plated satellite cell-derived myoblasts. (c) Immunoblot analysis clearly demonstrated efficient knockdown of BMPR-1A protein levels, which resulted in an upregulation of MyHC, but a downregulation of Pax7 ( $\beta$-tubulin served as a protein loading control). (d, quantified in e-g) The effects of BMPR-1A knockdown were also examined by immunostaining for Pax7, Ki67 or MyHC in plated satellite cell-derived myoblasts cultured in proliferation medium for 3 days after transfection. (d) Representative images of Ki67 and MyHC immunostaining show that BMPR-1A knockdown inhibited cell proliferation and promoted myogenic differentiation. (e and f) There was a significant decrease in the proportion of cells containing Pax7 or Ki67 (proliferating) after BMPR-1A siRNA-transfection. $(\mathbf{g})$ In contrast, there was a significant increase in the proportion of $\mathrm{MyHC}^{+}$differentiated cells and myotubes. Data are either mean \pm S.E.M. (b) or mean \pm S.D. $(\mathbf{e}-\mathbf{g})$ from at least three independent experiments. Asterisk denotes that data are significantly different from control $(P<0.05)$. Scale bar equals $50 \mu \mathrm{m}$ 
The efficient reduction in BMPR-1A levels by siRNA was confirmed by western blot analysis of plated satellite cells, which also revealed decreased Pax7 levels, but an increase in the amount of MyHC (Figure 4c). Immunostaining (Figure 4d, quantified in $\mathrm{e}-\mathrm{g}$ ) confirmed that reducing BMPR-1A led to a reduction in the proportion of $\mathrm{Pax} 7^{+}$ cells (Figure $4 \mathrm{e}$ ), which was accompanied by a significant reduction in $\mathrm{Ki}^{+} 7^{+}$proliferating cells (Figure 4d and f). In contrast, there was an increase in the proportion of $\mathrm{MyHC}^{+}$differentiated cells after BMPR-1A knockdown (Figure 4d and g).

Blockade of intracellular BMP signalling promotes myogenic differentiation. We next analysed the pSmad1/ $5 / 8$ signalling cascade. ${ }^{5}$ The protein kinase inhibitor Dorsomorphin is a specific inhibitor of Smad1/5/8 phosphorylation by BMPRs. ${ }^{26}$ Dorsomorphin $(1-5 \mu \mathrm{M})$ was not toxic to plated satellite cells, as shown using the Tunel assay (data not shown). Exposure of cultured myofibres to Dorsomorphin significantly decreased the mean number of associated $\mathrm{Pax}^{+}{ }^{+} \mathrm{MyoD}^{+}$satellite cells, and hence Pax7 $\mathrm{MyoD}^{+}$differentiating cells became the main phenotype (Figure 5a). Dorsomorphin also induced myogenic differentiation in a dose-dependent $(0.1-1.0 \mu \mathrm{M})$ manner in plated satellite cells maintained in proliferation medium (Figure 5b). Additionally, we also targeted Smad signalling using siRNA-mediated knockdown of Smad5 or Smad4, which effectively reduced the levels of the translated protein (Figure 5c and d). Co-immunostaining for Ki67 and MyHC revealed that Smad5 or Smad4 knockdown significantly reduced cell proliferation and induced precocious differentiation (Figure $5 \mathrm{e}$, quantified in $\mathrm{f}$ and $\mathrm{g}$ ).

BMP signalling regulates the ability of MyoD to activate its transcriptional targets. To understand how interference with BMP signalling promotes myogenic differentiation, we investigated Id1, a downstream target of $\mathrm{BMPs}^{6-8}$ and a negative controller of MyoD and myogenin. ${ }^{9,27}$ We recently showed that Id1 is highly expressed in proliferating satellite cells, before being downregulated during myogenic differentiation. ${ }^{25}$ Immunostaining showed that exposure to Dorsomorphin to inhibit Smad1/5/8 phosphorylation reduced Id1 levels in both satellite cells retained in their niche on the myofibre (Figure 6a) and in plated satellite cells (Figure 6b).

Muscle creatine kinase $(C K M)$ is a well-characterised gene and provides a useful tool to quantify both the ability of MyoD to transactivate its target genes, and myogenic differentiation. ${ }^{27}$ Therefore, we measured the activity of a CKMluciferase construct (CKM-LUCpCS2) in response to both exogenous Id1 and perturbation of BMP signalling (Figure $6 \mathrm{c}$ ). As expected, CKM-LUCpCS2 activity was significantly decreased after transfection with Id1 (Figure 6c). Importantly, transfection of a plasmid encoding a constitutively active BMPR-1A (caBMPR-1A) that phosphorylates Smad1/5/8 in the absence of BMP ligands ${ }^{28}$ also significantly reduced CKM-LUCpCS2 activity (Figure 6c). In contrast, inhibition of Smad1/5/8 phosphorylation with Dorsomorphin significantly increased the activity of CKM-LUCpCS2, but Id1 was able to completely reverse this Dorsomorphin-mediated increase (Figure 6c). Finally, caBMPR-1A also reduced
CKM-LUCpCS2 activity back to control levels, despite the presence of Dorsomorphin (Figure $6 \mathrm{c}$ ). Thus, BMP signalling in satellite cells acts to limit the transcriptional activation of genes controlled by MyoD and enhanced during differentiation.

Noggin antagonises BMPs to facilitate myogenic differentiation. Noggin is upregulated as satellite cells differentiate (Figure 2). To examine the role of Noggin, we first performed siRNA-mediated knockdown in plated satellite cells, and immunostaining showed that it worked efficiently (Figure 7a). Plated satellite cells transfected with Noggin siRNA and co-immunostained for Ki67 and MyHC (Figure 7b, quantified $\mathrm{c}-\mathrm{e}$ ) had a significantly increased proportion of proliferating $\mathrm{Ki}^{+} 7^{+}$satellite cells (Figure 7c). However, the proportion of differentiating $\mathrm{MyHC}^{+}$cells and the fusion index were both markedly reduced, with only myocytes or small myotubes present (Figure $7 \mathrm{~b}$ and e). Consistent with these observations, western blot analysis revealed a slight decrease in myogenin levels (Figure 7f). We also found that the fusion defect induced by Noggin knockdown could be rescued by Dorsomorphin-mediated blockade of intracellular BMP signalling (Figure 7g, quantified $h$ ), indicating that endogenous Noggin from differentiating cells is required for proper myotube formation, through suppression of BMP signalling.

BMP signalling is operative during muscle regeneration in vivo. Finally, we evaluated whether BMP signalling was also operative in satellite cells in regenerating muscle in vivo. Cardiotoxin was used to induce damage in the gastrocnemius muscle of adult mice. After 3 days, the regenerating muscles were removed, cryosectioned and immunostained for pSmad1/5/8, together with MyoD, to identify satellite cell-derived myoblasts: $97.4 \pm 2.9 \% \quad(n=50$ cells from each of 3 mice) of $\mathrm{MyoD}^{+}$cells contained pSmad1/5/8 (Figure 8a). Undamaged areas of the muscle periphery provided the control and no pSmad1/5/8 immunostaining was associated with myofibres in these non-regenerating regions (data not shown).

Regenerating gastrocnemius muscle was also injected with either $50 \mu \mathrm{l}$ of $10 \mu \mathrm{M}$ Dorsomorphin (Figure $8 \mathrm{~b}-\mathrm{d}$ ) or $50 \mu \mathrm{l}$ of $100 \mu \mathrm{g} / \mathrm{ml}$ sBMPR-1Af (Figure $8 \mathrm{e}-\mathrm{g}$ ) at 1 and 3 days after cardiotoxin-induced injury. The contralateral regenerating muscle served as the control and was injected with $50 \mu \mathrm{l}$ of vehicle. Regenerating muscles were removed on day 8 and immunostained for MyHC and collagen type 1 (Figure $8 \mathrm{~b}$ and e). Administration of Dorsomorphin resulted in a significant $\sim 20 \%$ decrease in the mean perimeter of centrally nucleated regenerating myofibres compared with controls, whereas the reduction was nearer $\sim 40 \%$ with sBMPR-1Af (Figure $8 \mathrm{c}$ and $\mathrm{f}$ ). A significant $\sim 1.5$-fold increase in collagen type 1 deposition after either Dorsomorphin or sBMPR-1Af administration was also observed (Figure 8d and $\mathrm{g}$ ).

\section{Discussion}

In this study, we investigated the role of BMP signalling in normal adult myogenesis. We found that exogenous BMP4 was able to sustain proliferation in satellite cells and inhibit differentiation. Conversely, blocking interaction of BMP with 
a

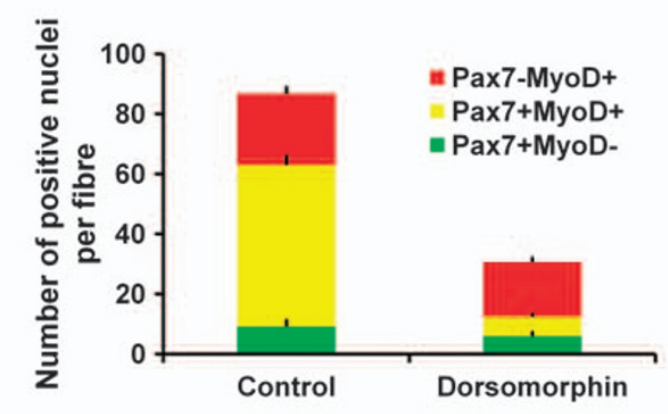

b

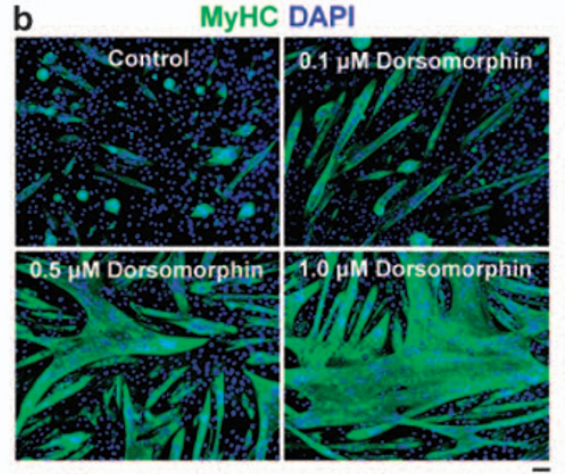

c
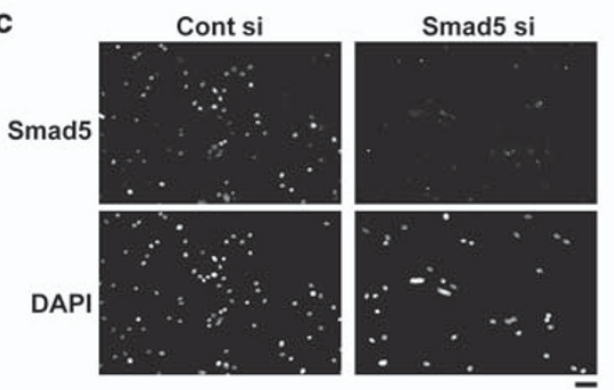

d
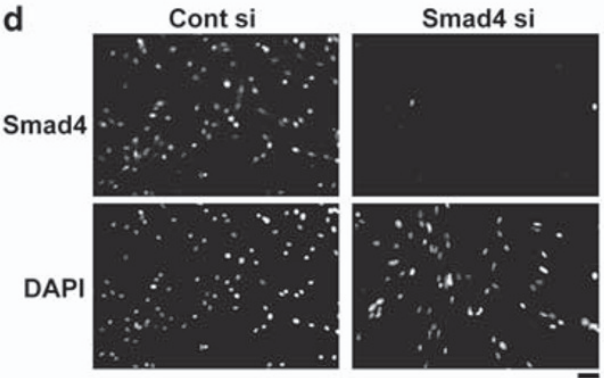

e
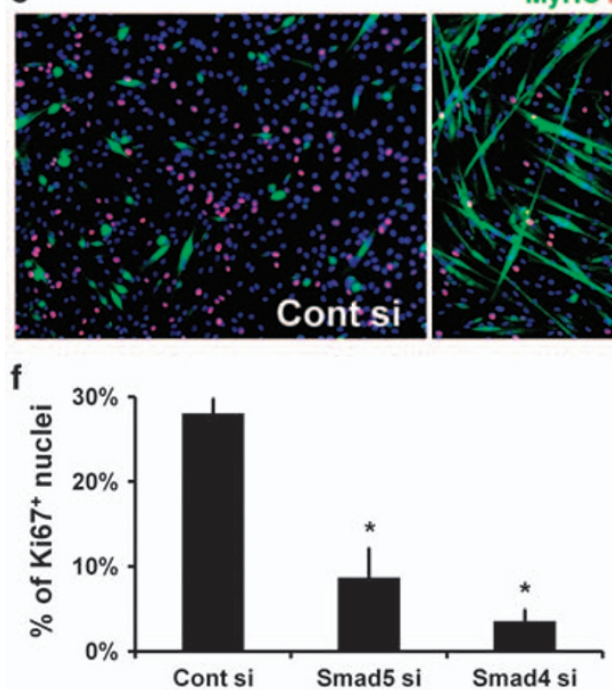

MyHC Ki67 DAPI
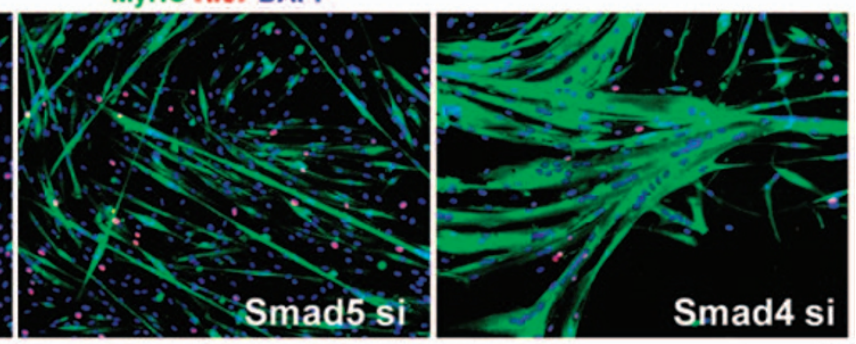

g

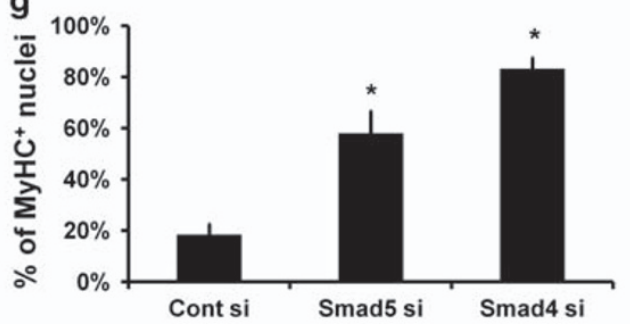

Figure 5 Inhibiting intracellular BMP signal mediation promotes myogenic differentiation. To inhibit BMP signaling, we used either Dorsomorphin, an inhibitor of Smad1/5/ 8 phosphorylation, or siRNA to knockdown the R-Smad, Smad5, or Co-Smad, Smad4, levels. (a) EDL myofibres and their associated satellite cells were cultured with or without $1 \mu \mathrm{M}$ Dorsomorphin and the plating medium changed daily. Dorsomorphin markedly decreased the mean total number of cells per fibre, particularly the number of cells with the $\mathrm{Pax} 7{ }^{+} \mathrm{MyoD}{ }^{+}$phenotype. (b) Satellite cell-derived myoblasts were plated at high cell density (80-90\% confluency) and cultured in proliferation medium for 2 days with or without Dorsomorphin. Immunostaining for MyHC showed that Dorsomorphin promoted myogenic differentiation and fusion in a dose-dependent manner. (c and d) Efficient siRNAmediated knockdown of Smad5 or Smad4 was confirmed by immunostaining of plated satellite cells $24 \mathrm{~h}$ after transfection. (e, quantified in $\mathbf{f}$ and $\mathbf{g}$ ) Co-immunostaining for MyHC and Ki67 after Smad5 or Smad4 silencing for 3 days in proliferation medium was sufficient to promote cell cycle exit and induce precocious differentiation, characterised by a decreased proportion of cells with $\mathrm{Ki}_{6} 7^{+}$expression and an increase in $\mathrm{MyHC}^{+}$cells and myotubes. Data are mean \pm S.E.M. (a) or mean \pm S.D. (f and $\mathbf{g}$ ) from at least three independent experiments. Asterisk indicates that data are significantly different from control conditions $(P<0.05)$. Scale bar equals $50 \mu \mathrm{m}$

its receptors, downregulating BMPR-1A or perturbing intracellular BMP signal mediation, all induced rapid differentiation. Thus, BMP signalling initially serves to allow expansion of the satellite cell pool by stimulating proliferation and preventing precocious myogenic differentiation (Figure 9).

The source of BMPs that act on satellite cells in vivo remains to be determined, but myogenic cells can express and secrete BMP4, ${ }^{29,30}$ with higher levels produced by myoblasts from dystrophic muscle. ${ }^{31}$ Additionally, muscle damage may also expose satellite cells to BMP4 in serum, ${ }^{23}$ and/or from cells such as macrophages, as microglia/ macrophages produce BMPs after CNS damage. ${ }^{32}$ Although prolonged exposure of myogenic cells to high levels of BMPs can induce expression of various osteogenic genes, ${ }^{16}$ we 
a
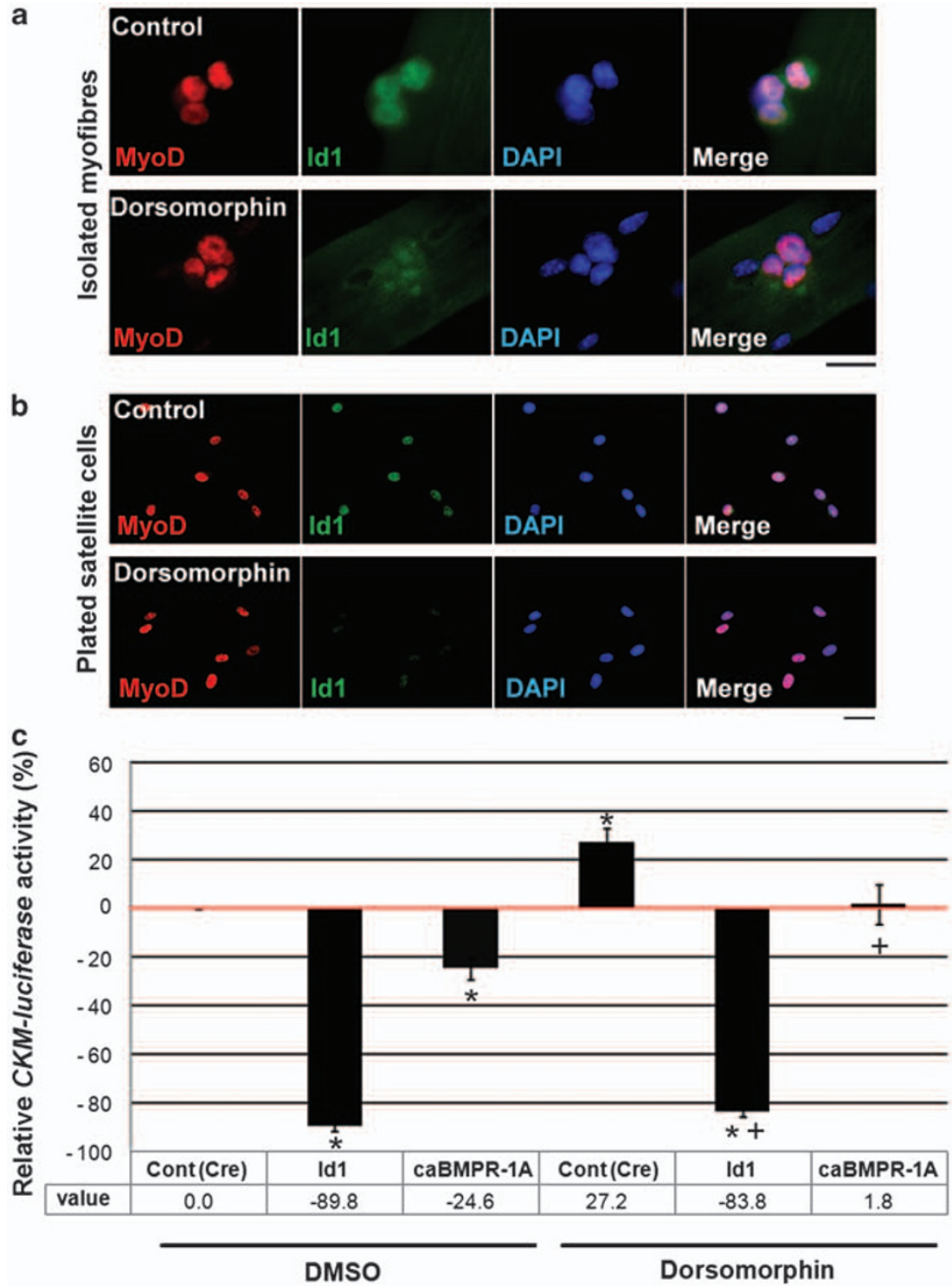

Figure 6 BMP signalling regulates the MyoD-controlled CKM promoter. Id1 is a target gene of BMP signalling and a negative regulator of MyoD activity. (a) Exposure to $3 \mu \mathrm{M}$ Dorsomorphin for $6 \mathrm{~h}$ to inhibit BMP signalling resulted in a downregulation of Id1 expression in satellite cells associated with a myofibre. (b) Similarly, immunostaining of plated satellite cells after exposure to $3 \mu \mathrm{M}$ Dorsomorphin for $18 \mathrm{~h}$ in proliferation medium also resulted in downregulation of Id 1 protein. Scale bar equals $20 \mu \mathrm{m}$. (c) To investigate the ability of MyoD to activate its transcriptional targets, plated satellite cell-derived myoblasts were transfected with a CKM (muscle creatine kinase) Luciferase reporter plasmid (CKM-LUCpCS2), whose activity is regulated by MyoD, together with a Renilla luciferase plasmid $p R L$ driven by a minimal tk promoter, as an internal control. Plated satellites cells were co-transfected with either Cre-expressing control plasmid or Id1-expressing plasmid or constitutively active BMPR-1A (caBMPR-1A)-expressing plasmid, together with CKM-LUCpCS2. After transfection, the cells were cultured in proliferation medium with or without $5 \mu \mathrm{M}$ Dorsomorphin for $24 \mathrm{~h}$ before reporter assay. Id1 or caBMPR-1A reduced CKM-LUCPCS2 activity. In contrast, inhibition of BMP signalling with Dorsomorphin had the opposite effect, and increased CKM-LUCPCS2 activity. Both Id 1 and caBMPR-1A were able to reverse this increase in CKM-LUCpCS2 activity produced by exposure to Dorsomophin. Data are represented as mean \pm S.D. from at least three independent experiments. Asterisk denotes that data are significantly different from control conditions, whereas a cross indicates that data are different from the level of CKM-LUCpCS2 activity in the presence of Dorsomorphin $(P<0.05)$, using Student's $t$-test

found that satellite cells exposed to BMP4 for shorter periods, likely encountered during muscle repair/regeneration in vivo, did not obviously compromise their myogenic identity.

Satellite cells respond to BMPs because they express BMPR-1A, which was undetectable on most quiescent satellite cells, but upregulated as cells were activated. An early event in satellite cell activation is induction of MyoD, which can bind to the promoter of $B M P R-1 A$ to enhance its expression, and MyoD overexpression leads to BMPR-1A induction. ${ }^{33}$ Thus upregulation of BMPR-1A is part of the response of satellite cells to serum stimulation, and siRNAmediated knockdown of BMPR-1A induced premature differentiation, showing that BMP signalling operates through BMPR-1A. Consistent with our observations, a dominantnegative BMPR-1A mutant enhanced myogenic differentiation in $\mathrm{C} 2$ cells maintained in high-serum medium, but a dominant-negative BMPR-1B mutant did not. ${ }^{23}$ In contrast, we found that a caBMPR-1 $\mathrm{A}^{28}$ reduced the activity of a CKM 
a
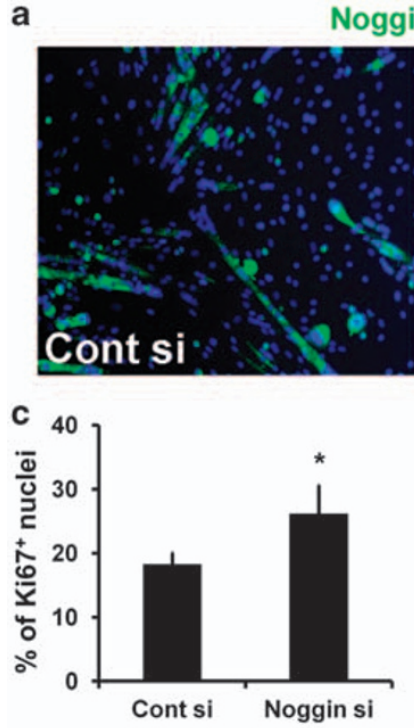

g

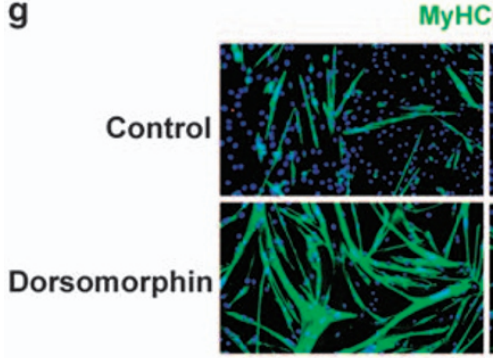

Cont si
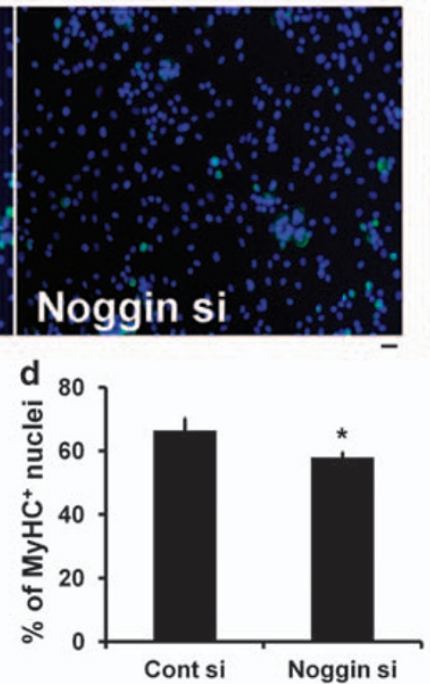

b
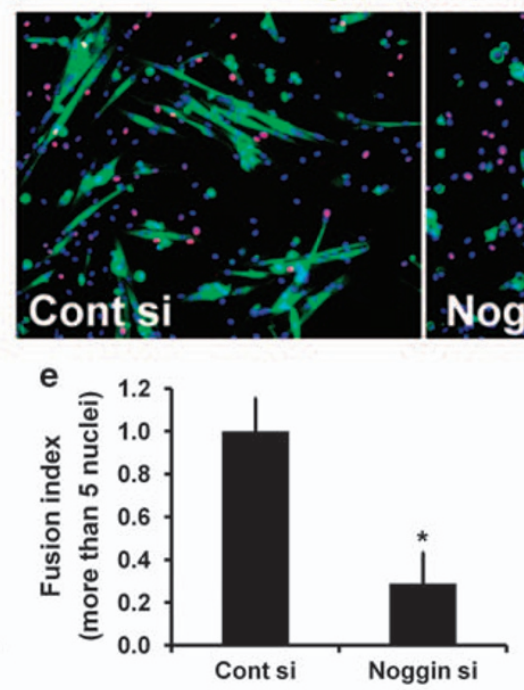

f

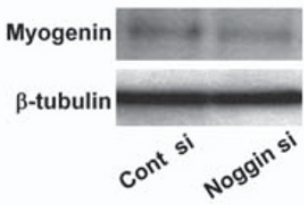

f

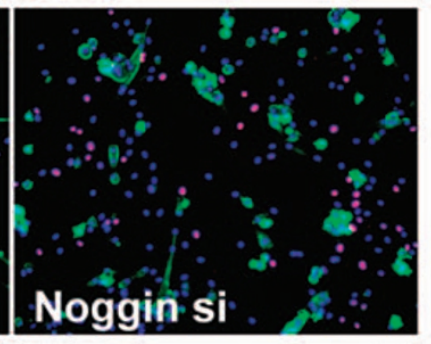

h
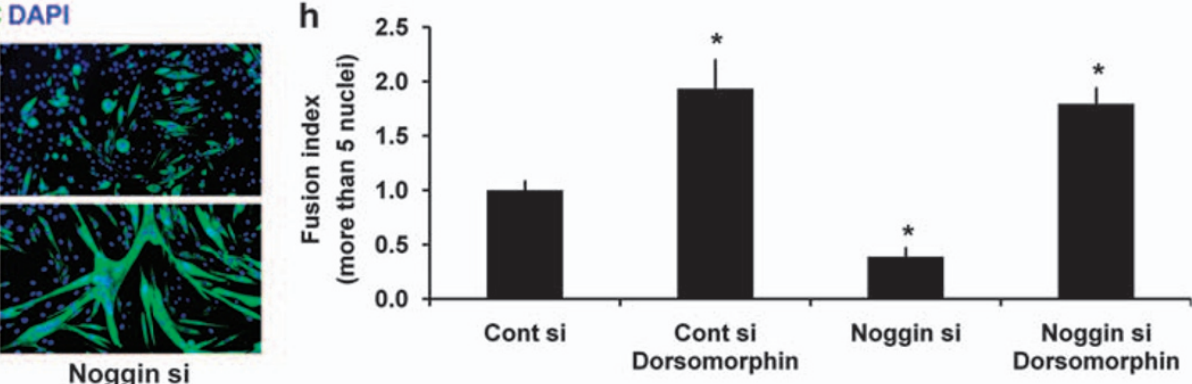

Figure 7 Reducing Noggin levels enhances satellite cell proliferation but inhibits differentiation. To further understand the role of Noggin in myogenic progression, we used siRNA-mediated knockdown of Noggin protein. (a) Efficient Noggin knockdown in plated satellite cell-derived myoblasts was confirmed by immunostaining for Noggin 3 days after siRNA (Noggin si) transfection. (b, quantified in c-e) The effects of Noggin knockdown were analysed by co-immunostaining for MyHC and Ki67, which revealed an increase in myoblast proliferation, but a reduction in differentiation and fusion into large myotubes. (f) Western blotting also showed that Noggin siRNA reduced myogenin levels in plated satellite cells. (g, quantified in $\mathbf{h}$ ) The effect of Dorsomorphin $(1 \mu \mathrm{M})$ treatment to inhibit BMP signalling on Noggin siRNA-transfected cells was analysed by immunostaining for MyHC. Dorsomorphin reversed the fusion defect induced by Noggin knockdown. Mean \pm S.D. from at least three independent experiments is shown. Asterisk indicates that data are significantly different from control $(P<0.05)$ using paired one-tail $t$-test. Scale bar equals $30 \mu \mathrm{m}$

reporter that is normally upregulated during myogenic differentiation.

BMPs are known to control the ability of MyoD to transactivate its target genes by Smad-mediated regulation of Id proteins, ${ }^{6-8}$ negative regulators of MyoD function and terminal differentiation. 9,27 Proliferating satellite cell-derived myoblasts contain both MyoD and Id1, with Id1 presumably curtailing MyoD function to prevent premature differentiation. Id1 levels are then dramatically reduced as satellite cells undergo differentiation. ${ }^{25}$ Consistent with these observations, although Id1 and Id3 are undetectable in muscle lysates from uninjured muscle, they are upregulated during muscle regeneration, peaking around day $3 .^{30}$ In satellite cells, we found that inhibiting BMP signalling reduced Id1 levels, promoted differentiation and increased CKM promoter activity.

Delta/Notch signalling permits satellite cell expansion and prevents precocious differentiation. ${ }^{34}$ Notch signalling is required for BMP4 to impede myogenic differentiation in $\mathrm{C} 2$ cells: inhibitors of $\gamma$-secretase prevent cleavage of Notch to release the active intracellular domain and can partially reverse the BMP-induced differentiation block. ${ }^{18}$ The catalytic subunit of the $\gamma$-secretase complex is presenilin-1, and we recently showed that presenilin-1 can inhibit satellite cell differentiation through both $\gamma$-secretase-dependent and $\gamma$-secretase-independent mechanisms. ${ }^{25}$ The $\gamma$-secretasedependent effects of presenilin-1 on impeding differentiation are likely through controlling Notch signalling. Crucially, however, the $\gamma$-secretase (Notch)-independent presenilin-1 mechanism operates by augmenting Pax7 and controlling Id1 levels, ${ }^{25}$ and intriguingly, Id1, Id2 and Id3 are direct transcriptional targets of Pax7. ${ }^{29}$ This $\gamma$-secretase-independent mechanism is unlikely to work through BMP signalling, however, as there is no difference in pSmad1/5/8 levels between presenilin-1-null or control embryonic fibroblasts transfected with MyoD, even though only the MyoD-expressing presenilin-1-null cells readily differentiate in high-serum medium (unpublished observations). Furthermore, overexpression of Wnt3a in $\mathrm{C} 2$ cells is capable of overcoming the BMP2-mediated block of differentiation by downregulating Id1. ${ }^{35}$ Thus $\gamma$-secretase-independent presenilin-1 signalling and the BMP pathway both seem to separately converge on Ids to regulate satellite cell function. 

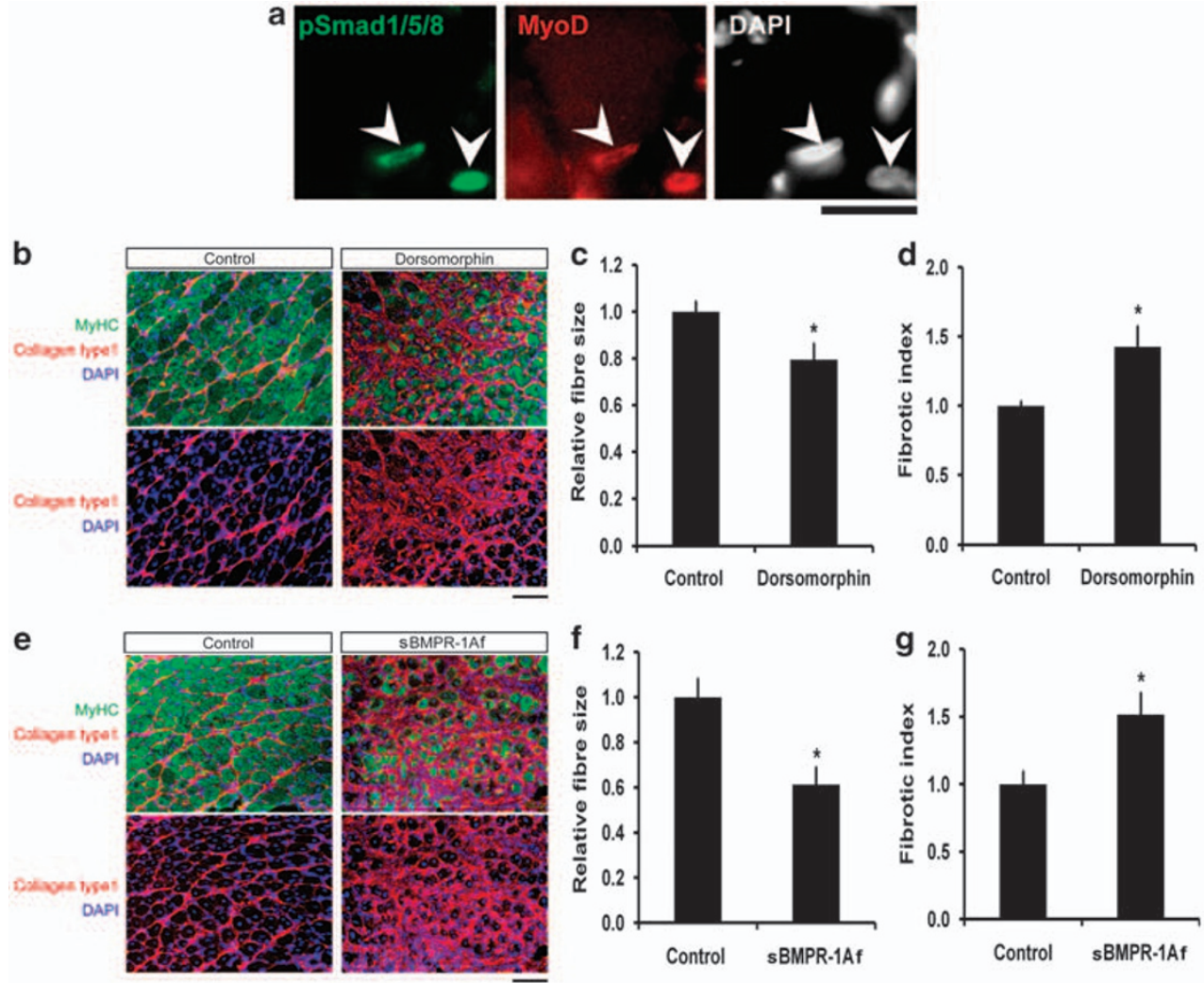

Figure 8 BMP signalling operates during normal muscle regeneration in vivo. Regeneration was induced in mouse gastrocnemius muscles by injection of cardiotoxin. (a) Satellite cell-derived myoblasts, identified by MyoD expression, also expressed pSmad1/5/8 (arrowheads) in regenerating muscle on day 3 of regeneration. (b-g) To examine the effects of blockade of BMP signalling, $50 \mu \mathrm{l}$ of $10 \mu \mathrm{M}$ Dorsomorphin/DMSO in saline or $50 \mu \mathrm{l}$ of $100 \mu \mathrm{g} / \mathrm{ml}$ sBMPR-1Af were intramuscularly injected into the right gastrocnemius, 1 and 3 days after cardiotoxin injection. Regenerating left gastrocnemius served as a control and received vehicle alone (DMSO/saline for Dorsomorphin or BSA solution for SBMPR-1Af). Muscle regeneration was assayed by immunostaining cryosections for MyHC and collagen type 1. (b, c,e and f) Treatment with either Dorsomorphin or sBMPR-1Af resulted in a significant decrease in the mean perimeter of centrally nucleated regenerating myofibres, compared with controls (100 regenerating fibres in the regenerating area of each animal were measured, and the mean size after exposure to Dorsomorphin or SBMPR-1Af expressed as the proportional change compared with the mean size of control regenerating myofibres). (b, $\mathbf{d}, \mathbf{e}$ and $\mathbf{g}$ ) Immunostaining for collagen type 1 was used to measure the degree of endomysial fibrosis, and a significant increase in the fibrotic index was observed in muscles exposed to either Dorsomorphin or sBMPR-1Af, compared with controls (the area of collagen type 1 expression in the regenerating area was measured in 1-3 sections for each animal, using Image $J$ and changes with exposure to Dorsomorphin or sBMPR-1 Af expressed as fold-difference compared with control). Six mice were used for each condition. Data are mean \pm S.E.M., where an asterisk denotes a significant difference from control $(P<0.05)$. Scale bars equal $100 \mu \mathrm{m}$

Antagonism of BMP signalling by Noggin is employed during development to protect pre-myogenic cells, and expansion of the Noggin expression domain promotes ectopic myogenesis. ${ }^{11,12}$ We found that Noggin-mediated interference with BMP signalling was also redeployed during adult myogenesis. Noggin was upregulated as satellite cells differentiated, and knocking down Noggin resulted in more cells proliferating, while fewer differentiated. As Noggin is a secreted signalling molecule, it may also act in a paracrine manner to reduce BMP signalling in proliferating cells to potentiate and augment timely differentiation. Noggin expression in C2 cells is upregulated by exogenous BMP $2,{ }^{36}$ and administration of Noggin to regenerating muscle reduces both $\mathrm{pSmad} 1 / 5 / 8$ and Id 1 levels. ${ }^{30}$ In addition, rhabdomyosarcoma cells express myogenic genes including MyoD and myogenin but form myotubes poorly, and have relatively high levels of BMP4 and lower expression of Noggin than primary myoblasts. ${ }^{37}$ Furthermore, specification of myogenic cells is unaffected in Noggin-null embryos, but differentiation is clearly perturbed, with meagre myotube formation during foetal myogenesis, ${ }^{38}$ again suggesting a common role for
Noggin in supporting differentiation in both developmental and adult myogenesis.

We observed that inhibition of BMP signalling during muscle regeneration resulted in smaller regenerated myofibres. Similarly, $I d 1^{-1+} I d 3^{-/-}$mice also exhibit a muscle regeneration defect, with the cross-sectional area of regenerated myofibres being only $\sim 50 \%$ of wild type. ${ }^{30}$ These mice also had fewer proliferating satellite cells during regeneration. ${ }^{30}$

In conclusion, BMP signalling is part of the programme that regulates routine satellite cell function. BMPs stimulate proliferation and prevent precocious differentiation to allow amplification of satellite cell-derived myoblasts. Noggin is then upregulated as satellite cell progeny differentiate, to antagonise BMP signalling and facilitate coordinated differentiation (Figure 9).

\section{Materials and Methods}

Isolation and culture of primary satellite cells and myoblasts. Adult (8-12 weeks old) C57BL10 mice were killed by cervical dislocation, and the EDL (or masseter for Figure $3 \mathrm{~b}$ only) muscle isolated and 


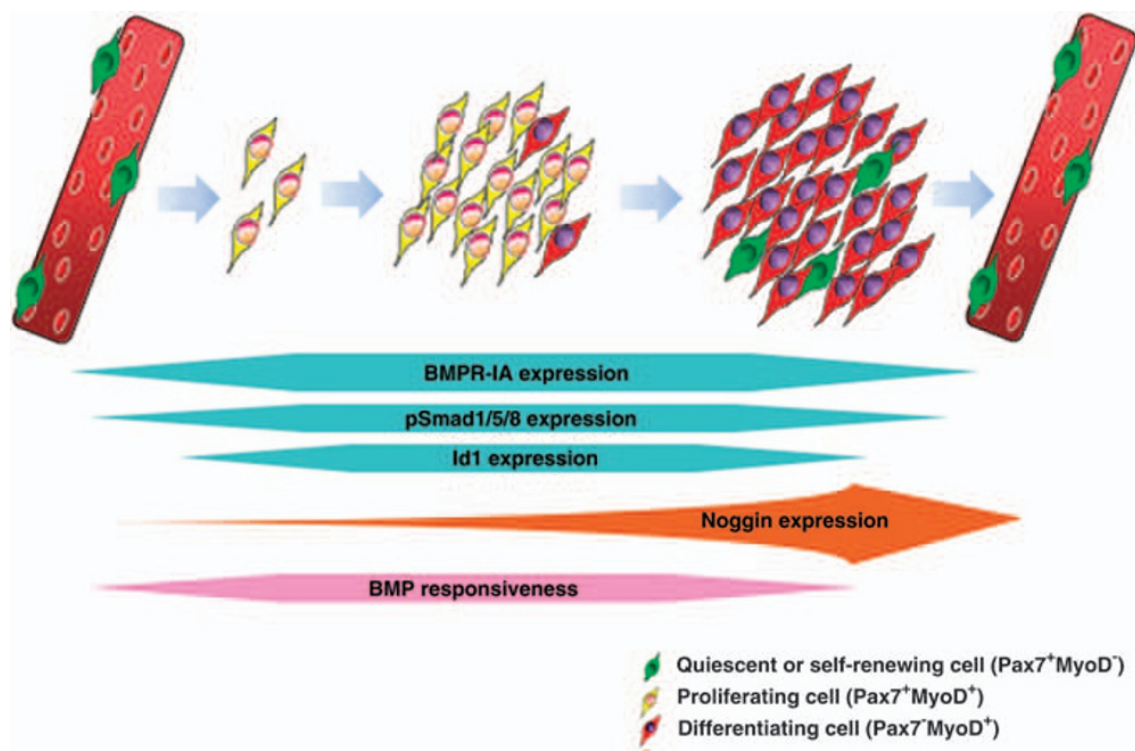

Figure 9 Role of BMP signalling during myogenic progression in satellite cells. During muscle repair and regeneration, quiescent Pax $7^{+}$satellite cells are activated to coexpress Pax7 and MyoD. Satellite cell-derived myoblasts proliferate extensively before many cells then downregulate Pax7 and differentiate to either repair damaged muscle fibres or fuse together to generate new myofibres. Other satellite cells maintain Pax7 expression but lose MyoD, and self-renew to maintain a viable stem cell compartment. Normal BMP signalling through BMPR-1A and Smad1/5/8 phosphorylation is required during muscle repair/regeneration to allow the satellite cell-derived myoblast population to expand, by preventing precocious differentiation. BMP signalling operates through controlling Id levels, a negative regulator of MyoD and myogenic differentiation. As satellite cell progeny differentiate, Noggin is upregulated to antagonise the BMP signal, so facilitating the myogenic differentiation programme

digested in collagenase type1, as previously described. ${ }^{25}$ Most satellite cells are mitotically quiescent in healthy adult muscle, so must first be activated and will then enter the cell cycle. ${ }^{2}$ To induce satellite cell activation in vitro, myofibers and associated satellite cells were cultured in plating medium (DMEM supplemented with L-glutamine or GlutaMax (Sigma, Poole, Dorset, UK), 10\% horse serum (PAA Laboratories, Yeovil, Somerset, UK), $0.5 \%$ chicken embryonic extract (MTX Lab Systems, Vienna, VA, USA) and $1 \%$ penicillin-streptomycin (Sigma)) at $37^{\circ} \mathrm{C}$ in $5 \%$ $\mathrm{CO}_{2}$, as described previously. ${ }^{24}$ To prepare plated satellite cells, either cells were removed from myofibers by enzymatic treatment with $0.125 \%$ trypsin-EDTA (Sigma) for $10 \mathrm{~min}$ at $37^{\circ} \mathrm{C}$ or allowed to migrate from isolated myofibres cultured on Matrigel. Satellite cells were then re-plated on Matrigel at equal density and maintained in proliferation medium (DMEM supplemented with L-glutamine or GlutaMAX, $20-30 \%$ foetal bovine serum, $1 \%$ chicken embryo extract, $10 \mathrm{ng} / \mathrm{ml}$ bFGF and $1 \%$ penicillin-streptomycin). Satellite cells were treated with $100 \mathrm{ng} / \mathrm{ml}$ recombinant BMP4 protein, (Peprotech, London, UK), $50 \mathrm{ng} / \mathrm{ml}$ recombinant Noggin protein (Peprotech), $200 \mathrm{ng} / \mathrm{ml}$ sBMPR-1Af (R\&D systems, Abingdon, Oxfordshire, UK) or $0.1-3 \mu \mathrm{M}$ Dorsomorphin (also known as Compound C; CalbiochemMERCK-Beeston, Nottingham, UK) administered to the culture medium. In other experiments, satellite cells were switched from proliferation medium to differentiation medium (DMEM with L-glutamine or GlutaMax and supplemented with $2 \%$ horse serum and $1 \%$ penicillin-streptomycin) and cultured for $48 \mathrm{~h}$ with or without BMP4 $(200 \mathrm{ng} / \mathrm{ml})$. Myofibres and associated satellite cells or plated satellite cells were fixed with warm $4 \%$ paraformaldehyde (PFA).

Antibodies used in the study. Antibodies were obtained from the following sources. Rabbit anti-BMPR-1A (Alk-3) from Orbigen (San Diego, CA, USA) and a gift from Professor B. Kay; ${ }^{39}$ rat anti-Ki67 from DakoCytomation (Ely, Cambridgeshire, UK); goat anti-Smad5, mouse anti-Smad4, mouse anti-MyoD and rabbit anti-MyoD antibodies were obtained from Santa Cruz (Santa Cruz, USA); goat anti-Noggin antibody was obtained from R\&D systems; mouse anti-MyHC (MF20), anti-Pax7, antimyogenin (F5D) and anti- $\beta$-tubulin antibodies (E7) were supplied by the DSHB (lowa City, IA, USA); rabbit anti-pSmad1/5/8 antibody was from Cell Signalling Technology (Beverly, MA, USA); goat anti-collagen type 1 antibody was acquired from Southern Biotech (Bimingham, AL, USA). Mounting medium containing 4,6-diamidino-2phenylindole (DAPI) to counterstain all nuclei and the M.O.M kit were both purchased from Vector Laboratories, Orton Southgate, Peterborough, UK.

Immunoblot analysis. Immunoblot analysis was performed as previously described ${ }^{25}$ Anti-BMPR-1A, anti-MyHC, anti-Pax7, anti-Myogenin or anti- $\beta$-tubulin antibodies were applied in PBS containing $0.1 \%$ Tween20 and incubated at $4{ }^{\circ} \mathrm{C}$ overnight. HRP-conjugated secondary antibodies were used for visualisation by chemiluminescence (Fujifilm, Bedford, UK).

Immunostaining. Immunocytochemistry was as previously described. ${ }^{25}$ AntiBMPR-1A, anti-Ki67, anti-Smad5, anti-Smad4, anti-MyoD, anti-Noggin, anti-MyHC anti-Pax7, anti-myogenin, anti-Id1 or anti-pSmad1/5/8 antibodies were applied at $4^{\circ} \mathrm{C}$ overnight. For co-immunostaining sections, frozen regenerating muscle crosssections were fixed with 4\% PFA, blocked using the M.O.M kit and incubated with either anti-pSmad1/5/8 and anti-MyoD antibodies or with anti-MyHC and anticollagen type 1 antibodies. Immunostained myofibres, plated cells or cryosections were viewed on a Zeiss Axiophot 200M using Plan-Neofluar lenses (Zeiss, Welwyn Garden City, Hertfordshire, UK), or on a Nikon (Kingston upon Thames, Surrey, UK) C1si confocal using Plan-Fluor lenses. Digital images were acquired with a Zeiss AxioCam HRm Charge-Coupled Device using AxioVision software version 4.4. Images were optimised globally and assembled into figures using Adobe Photoshop. The Click-iT Tunel Alexa fluor imaging assay (Invitrogen, Life Technologies, Paisley, UK) was used as per the manufacturer's instructions on satellite cells cultured for $24 \mathrm{~h}$ in proliferation medium containing either $1 \mu \mathrm{M}$ or $5 \mu \mathrm{M}$ Dorsomorphin ( $n=3$ mice)

CKM-luciferase reporter assay. Plated satellite cells were co-transfected with the CKM firefly Luciferase reporter plasmid (CKM-LUCpCS2) and pcDNA3-Creexpressing control vector, $p c D N A 3$-mld1-expressing vector ${ }^{27}$ or $p c D E F 3$-caBMPR$1 A$-expressing vector, ${ }^{7}$ using Lipofectamine LTX according to the manufacturer's instructions. The Renilla luciferase plasmid $p R L$ (Promega Corporation, Madison, WI, USA), driven by a minimal tk promoter, was included as an internal control. Dorsomorphin was added to a final concentration of $5 \mu \mathrm{M}$. At $48 \mathrm{~h}$ post-transfection, the dual-Luciferase reporter assay (Promega) was performed according to the manufacturer's instructions and measured on an Anthos Lucy3 (JENCONS-PLS, East Grinstead, West Sussex, UK).

siRNA-mediated gene knockdown. The transfection of siRNA (Invitrogen Life Technologies) into primary satellite cell-derived myoblasts was performed using Lipofectamine 2000 reagent (Invitrogen Life Technologies) or Lipofectamine RNAiMAX (Invitrogen Life Technologies) as previously described. ${ }^{25}$ Transfection of siRNA into single myofibers was carried out $12-16 \mathrm{~h}$ after isolation with Lipofectamine RNAiMAX (Invitrogen Life Technologies). ${ }^{25}$ All samples were examined 1-3 days after the transfection. The following siRNA sequences were 
used: BMPR-1A siRNA: $5^{\prime}$-GAAGUGCUGGAUGAAAGCCUGAAUA-3', Smad4 siRNA: 5'-GGAGAGACGUUUAAGGUCCCUUCAA-3', Smad5 siRNA: 5'-CCUG GGAUUGUUGUCAAAUGUUAAU-3' and Noggin siRNA: $5^{\prime}$-CGACCCGGG CUUUAUGGCUACUUCG-3'. Control siRNAs were supplied by Invitrogen Life Technologies.

Muscle regeneration studies. Animal husbandry, breeding and experimental procedures were passed by the Ethical Review Process Committee of the King's College London, and were carried out in accordance with British law under the provisions of the Animals (Scientific Procedures) Act 1986. To assay pSmad1/5/8 expression, the gastrocnemius muscle of 10-week-old male C57BL/10 mice was injected with $50 \mu \mathrm{l}$ of $10 \mu \mathrm{M}$ cardiotoxin (Sigma) using a 29-G 1/2 insulin syringe. Muscles were removed 3 days later and immediately frozen in isopentane cooled in liquid nitrogen, and stored at $-80^{\circ} \mathrm{C}$ before being cryosectioned and immunostained for $\mathrm{pSmad1/5/8}$ and MyoD. To assay regenerative capacity in the presence of perturbed BMP signalling, the belly of both the left and right gastrocnemius muscles of 7- to 9-week-old male C57BL/10 mice were injected with $25 \mu \mathrm{l}$ of $10 \mu \mathrm{M}$ cardiotoxin (Sigma). At 1 and 3 days after cardiotoxin injection, $50 \mu \mathrm{l}$ of $10 \mu \mathrm{M}$ Dorsomorphin/DMSO dissolved in saline or $50 \mu \mathrm{l}$ of $100 \mu \mathrm{g} / \mathrm{ml}$ sBMPR-1Af dissolved in saline, were injected intramuscularly into the right gastrocnemius muscle at the same site as the cardiotoxin. Control solutions (same concentration of DMSO dissolved in saline for Dorsomorphin or BSA dissolved in saline for SBMPR1Af) were injected into the left muscle as a control. Muscles were removed 8 days after cardiotoxin injection and immediately frozen in isopentane cooled in liquid nitrogen and stored at $-80^{\circ} \mathrm{C}$ Transverse sections of muscle were cut with a cryostat and co-immunostained for MyHC and collagen type 1. Measurement of centrally nucleated regenerating myofibres and the area of endomysial fibrosis was performed using ImageJ software (developed by $\mathrm{NIH}$ and available for free download at http://rsb.info.nih.gov/ij).

Statistical analysis. Data are presented as mean \pm standard deviation (S.D.) or mean \pm standard error (S.E.M.). Immunostained satellite cells from at least 10 myofibres were scored from each of at least three mice for each experiment. Significant differences between test conditions and controls were determined using Student $t$-test, wherein $P$-values $<0.05$ were considered to be statistically significant.

\section{Conflictal of interest}

The authors declare no conflict of interest.

Acknowledgements. We thank Dr. Stephen J. Tapscott for providing the CKM-LUCpCS2 reporter plasmid; Dr. Robert Benezra for generously sharing pcDNA3-mld1 construct; Dr. Naohiro Hashimoto for helpful discussions and Paul Knopp for much help. We gratefully acknowledge colleagues who shared antibodies, including through the Developmental Studies Hybridoma Bank developed under the auspices of the NICHD and maintained by the University of lowa. Y.O. was funded by the Muscular Dystrophy Campaign (RA3/737); F.C. is sponsored by the Association of International Cancer Research (07-0151); J.E.M. is backed by a Wellcome Trust university award. The laboratory of P.S.Z. is also supported by The Wellcome Trust, The Medical Research Council, the MYORES Network of Excellence (contract 511978) from the European Commission 6th Framework Programme and the collaborative Project OPTISTEM (Grant Agreement number: 223098) from the European Commission 7th Framework Programme.

1. Zammit PS. All muscle satellite cells are equal, but are some more equal than others? J Cell Sci 2008; 121: 2975-2982.

2. Zammit PS, Golding JP, Nagata Y, Hudon V, Partridge TA, Beauchamp JR. Muscle satellite cells adopt divergent fates: a mechanism for self-renewal? J Cell Biol 2004; 166 347-357.

3. Halevy O, Piestun Y, Allouh MZ, Rosser BW, Rinkevich Y, Reshef R et al. Pattern of Pax 7 expression during myogenesis in the posthatch chicken establishes a model for satellite cell differentiation and renewal. Dev Dyn 2004; 231: 489-502.

4. Collins CA, Olsen I, Zammit PS, Heslop L, Petrie A, Partridge TA et al. Stem cell function, self-renewal, and behavioral heterogeneity of cells from the adult muscle satellite cell niche. Cell 2005; 122: 289-301.

5. Feng $\mathrm{XH}$, Derynck R. Specificity and versatility in TGF-beta signaling through Smads. Annu Rev Cell Dev Biol 2005; 21: 659-693.
6. Hollnagel A, Oehlmann V, Heymer J, Ruther U, Nordheim A. Id genes are direct targets of bone morphogenetic protein induction in embryonic stem cells. J Biol Chem 1999; 274: 19838-19845.

7. Katagiri T, Imada M, Yanai T, Suda T, Takahashi N, Kamijo R. Identification of a BMPresponsive element in Id1, the gene for inhibition of myogenesis. Genes Cells 2002; 7: 949-960.

8. Korchynskyi $\mathrm{O}$, ten Dijke $\mathrm{P}$. Identification and functional characterization of distinct critically important bone morphogenetic protein-specific response elements in the Id1 promoter. J Biol Chem 2002; 277: 4883-4891.

9. Jen $\mathrm{Y}$, Weintraub $\mathrm{H}$, Benezra $\mathrm{R}$. Overexpression of Id protein inhibits the muscle differentiation program: in vivo association of Id with E2A proteins. Genes Dev 1992; 6 : 1466-1479

10. Wozney JM, Rosen V, Celeste AJ, Mitsock LM, Whitters MJ, Kriz RW et al. Novel regulators of bone formation: molecular clones and activities. Science 1988; 242: 1528-1534.

11. Reshef R, Maroto M, Lassar AB. Regulation of dorsal somitic cell fates: BMPs and Noggin control the timing and pattern of myogenic regulator expression. Genes Dev 1998; 12 : 290-303

12. Réem-Kalma Y, Lamb T, Frank D. Competition between noggin and bone morphogenetic protein 4 activities may regulate dorsalization during Xenopus development. Proc Natl Acad Sci USA 1995; 92: 12141-12145.

13. Hirsinger E, Duprez D, Jouve C, Malapert P, Cooke J, Pourquie O. Noggin acts downstream of Wnt and Sonic Hedgehog to antagonize BMP4 in avian somite patterning. Development 1997; 124: 4605-4614.

14. Amthor $\mathrm{H}$, Christ $\mathrm{B}$, Weil $\mathrm{M}$, Patel $\mathrm{K}$. The importance of timing differentiation during limb muscle development. Curr Biol 1998; 8: 642-652.

15. Wada MR, Inagawa-Ogashiwa $M$, Shimizu $S$, Yasumoto $S$, Hashimoto $N$. Generation of different fates from multipotent muscle stem cells. Development 2002; 129: 2987-2995

16. Katagiri $\mathrm{T}$, Yamaguchi A, Komaki M, Abe E, Takahashi N, lkeda $T$ et al. Bone morphogenetic protein-2 converts the differentiation pathway of $\mathrm{C} 2 \mathrm{C} 12$ myoblasts into the osteoblast lineage. J Cell Biol 1994; 127: 1755-1766.

17. Asakura A, Komaki M, Rudnicki M. Muscle satellite cells are multipotential stem cells that exhibit myogenic, osteogenic, and adipogenic differentiation. Differentiation 2001; 68: 245-253.

18. Dahlqvist C, Blokzijl A, Chapman G, Falk A, Dannaeus K, lbanez CF et al. Functional Notch signaling is required for BMP4-induced inhibition of myogenic differentiation. Development 2003; 130: 6089-6099.

19. Kaplan FS, Shen Q, Lounev V, Seemann P, Groppe J, Katagiri T et al. Skeletal metamorphosis in fibrodysplasia ossificans progressiva (FOP). J Bone Miner Metab 2008; 26: $521-530$

20. Lounev VY, Ramachandran R, Wosczyna MN, Yamamoto M, Maidment AD, Shore EM et al. Identification of progenitor cells that contribute to heterotopic skeletogenesis. J Bone Joint Surg Am 2009; 91: 652-663.

21. Yu PB, Deng DY, Lai CS, Hong CC, Cuny GD, Bouxsein ML et al. BMP type I receptor inhibition reduces heterotopic ossification. Nat Med 2008; 14: 1363-1369.

22. Namiki M, Akiyama S, Katagiri T, Suzuki A, Ueno N, Yamaji $\mathrm{N}$ et al. A kinase domaintruncated type I receptor blocks bone morphogenetic protein-2-induced signal transduction in C2C12 myoblasts. J Biol Chem 1997; 272: 22046-22052.

23. Kodaira K, Imada M, Goto M, Tomoyasu A, Fukuda T, Kamijo R et al. Purification and identification of a BMP-like factor from bovine serum. Biochem Biophys Res Commun 2006; 345: 1224-1231.

24. Ono Y, Boldrin L, Knopp P, Morgan JE, Zammit PS. Muscle satellite cells are a functionally heterogeneous population in both somite-derived and branchiomeric muscles. Dev Biol 2010; 337: 29-41.

25. Ono Y, Gnocchi VF, Zammit PS, Nagatomi R. Presenilin-1 acts via Id1 to regulate the function of muscle satellite cells in a gamma-secretase-independent manner. J Cell Sci 2009; 122: 4427-4438.

26. Yu PB, Hong CC, Sachidanandan C, Babitt JL, Deng DY, Hoyng SA et al. Dorsomorphin inhibits BMP signals required for embryogenesis and iron metabolism. Nat Chem Biol 2008; 4: 33-41.

27. Benezra R, Davis RL, Lockshon D, Turner DL, Weintraub $H$. The protein Id: a negative regulator of helix-loop-helix DNA binding proteins. Cell 1990; 61: 49-59.

28. Akiyama S, Katagiri T, Namiki M, Yamaji N, Yamamoto N, Miyama $\mathrm{K}$ et al. Constitutively active BMP type I receptors transduce BMP-2 signals without the ligand in $\mathrm{C} 2 \mathrm{C} 12$ myoblasts. Exp Cell Res 1997; 235: 362-369.

29. Kumar D, Shadrach JL, Wagers AJ, Lassar AB. Id3 is a direct transcriptional target of Pax7 in quiescent satellite cells. Mol Biol Cell 2009; 20: 3170-3177.

30. Clever JL, Sakai Y, Wang RA, Schneider D. Inefficient skeletal muscle repair in inhibitor of differentiation (Id) knockout mice suggests a crucial role for bmp signaling during adult muscle regeneration. Am J Physiol Cell Physiol 2010; 298: C1087-C1099.

31. Sterrenburg E, van der Wees CG, White SJ, Turk R, de Menezes RX, van Ommen GJ et al. Gene expression profiling highlights defective myogenesis in DMD patients and a possible role for bone morphogenetic protein 4. Neurobiol Dis 2006; 23: 228-236. 
32. Xiao Q, Du Y, Wu W, Yip HK. Bone morphogenetic proteins mediate cellular response and, together with Noggin, regulate astrocyte differentiation after spinal cord injury. Exp Neurol 2010; 221: 353-366.

33. Liu R, Ginn SL, Lek M, North KN, Alexander IE, Little DG et al. Myoblast sensitivity and fibroblast insensitivity to osteogenic conversion by BMP-2 correlates with the expression of Bmpr-1a. BMC Musculoskelet Disord 2009; 10: 51

34. Conboy IM, Rando TA. The regulation of Notch signaling controls satellite cell activation and cell fate determination in postnatal myogenesis. Dev Cell 2002; 3: 397-409.

35. Nakashima A, Katagiri T, Tamura M. Cross-talk between Wnt and bone morphogenetic protein 2 (BMP-2) signaling in differentiation pathway of $\mathrm{C} 2 \mathrm{C} 12$ myoblasts. J Biol Chem 2005; 280: 37660-37668.
36. Takayama K, Suzuki A, Manaka T, Taguchi S, Hashimoto Y, Imai Y et al. RNA interference for noggin enhances the biological activity of bone morphogenetic proteins in vivo and in vitro. J Bone Miner Metab 2009; 27: 402-411.

37. Goldstein M, Meller I, Orr-Urtreger A. FGFR1 over-expression in primary rhabdomyosarcoma tumors is associated with hypomethylation of a $5^{\prime} \mathrm{CpG}$ island and abnormal expression of the AKT1, NOG, and BMP4 genes. Genes Chromosomes Cancer 2007; 46: 1028-1038.

38. Tylzanowski $P$, Mebis L, Luyten FP. The Noggin null mouse phenotype is strain dependent and haploinsufficiency leads to skeletal defects. Dev Dyn 2006; 235: 1599-1607.

39. Kariyawasam HH, Xanthou G, Barkans J, Aizen M, Kay AB, Robinson DS. Basal expression of bone morphogenetic protein receptor is reduced in mild asthma. Am J Respir Crit Care Med 2008; 177: 1074-1081. 